\title{
Homeostatic imbalance and colon cancer: the dynamic epigenetic interplay of inflammation, environmental toxins, and chemopreventive plant compounds
}

\section{Melissa L. Sokolosky and Michael J. Wargovich*}

Department of Cell and Molecular Pharmacology and Experimental Therapeutics, Hollings Cancer Center, Medical University of South Carolina, Charleston, SC, USA

\section{Edited by:}

Inti Zlobec, University of Bern,

Switzerland

\section{Reviewed by:}

Inti Zlobec, University of Bern, Switzerland

Parham Minoo, University of

California San Diego, USA

\section{*Correspondence:}

Michael J. Wargovich, Department of Cell and Molecular Pharmacology, Hollings Cancer Center, Medical University of South Carolina, 86 Jonathan Lucas Street, Charleston, SC 29245, USA.

e-mail:wargovic@musc.edu
The advent of modern medicine has allowed for significant advances within the fields of emergency care, surgery, and infectious disease control. Health threats that were historically responsible for immeasurable tolls on human life are now all but eradicated within certain populations, specifically those that enjoy higher degrees of socio-economic status and access to healthcare. However, modernization and its resulting lifestyle trends have ushered in a new era of chronic illness; one in which an unprecedented number of people are estimated to contract cancer and other inflammatory diseases. Here, we explore the idea that homeostasis has been redefined within just a few generations, and that diseases such as colorectal cancer are the result of fluctuating physiological and molecular imbalances. Phytochemical-deprived, pro-inflammatory diets combined with low-dose exposures to environmental toxins, including bisphenol-A (BPA) and other endocrine disruptors, are now linked to increasing incidences of cancer in westernized societies and developing countries. There is recent evidence that disease determinants are likely set in utero and further perpetuated into adulthood dependent upon the innate and environmentally-acquired phenotype unique to each individual. In order to address a disease as multi-factorial, case-specific, and remarkably adaptive as cancer, research must focus on its root causes in order to elucidate the molecular mechanisms by which they can be prevented or counteracted via plant-derived compounds such as epigallocatechin-3-gallate (EGCG) and resveratrol. The significant role of epigenetics in the regulation of these complex processes is emphasized here to form a comprehensive view of the dynamic interactions that influence modern-day carcinogenesis, and how sensibly restoring homeostatic balance may be the key to the cancer riddle.

Keywords: colon cancer, inflammation, cancer stem cell, environmental toxin, xenoestrogen, phytochemical, epigenetic, chemoprevention

\section{MODERNIZATION, ACCULTURATION, AND RISK FOR COLORECTAL CANCER}

Human homeostasis, defined as the internal state necessary for establishing systemic equilibrium and maintaining stability, has arguably shifted in less than a century. It is well documented that individuals adhering to a phytochemical-depleted diet and relatively sedentary lifestyle are more likely to develop obesity, contract chronic conditions such as diabetes, cardiovascular disease, and cancer, and spend a significant segment of their later lives dependent upon health care and pharmaceuticals. Trends in consumerism and shifts in societal preferences toward convenience and modernization continue to peak in the United States and other "westernized" countries, and are now apparent in developing countries around the world. So are the trends for cancer incidence. In 2008, an estimated 1.234 million cases of colorectal cancer occurred worldwide, with $60 \%$ of these cases arising in developed regions (GLOBOCAN Colorectal Cancer Data, 2008). Between the years of 1983-1987 and 1998-2002, colorectal cancer incidence rates for both genders increased in 27 out of 51 registries of the IARC, most notably within regions of recent urbanization and economic transition such as most of Asia and numerous South American countries (Center et al., 2009).

When incidence, death, and 5-year prevalence rates are examined among world cultures ranging from traditional to modern, the differences in statistics are startling. The three regions with the lowest rates (East Mediterranean, African, and Indian) had on average a 26 -fold lower incidence rate, a 16 -fold decrease in related death, and a substantial 41-times lower 5-year prevalence of colorectal cancer when compared to rates within the category of "more developed regions" (GLOBOCAN Colorectal Cancer Data, 2008). It is interesting to note that cultures exhibiting the lowest rates of colorectal cancer are also more likely to follow a pastoral way of life reflecting reliance upon the natural world. The reduced risks of cancer and other chronic diseases enjoyed by these individuals are attributable in some ways to genetic disposition, but also correlate largely with environmental factors arising from their retention of preventive dietary and lifestyle practices; the same practices that have allowed human beings to utilize their 
environments in order to survive them throughout the course of evolution. However, considering the pace at which urbanization, industrialization, and technology spread in the twentieth century, a historically unprecedented scenario of environmental exposures has emerged within a timeframe too rapid for an appropriate adaptive physiological response. Therefore, the recent shift away from "low risk" lifestyles has promoted persistent pro-disease phenotypes within certain populations that are concerning and costly in terms of time, resources, and quality of life.

Age-standardized incidences for colorectal cancer, as well as most other cancers, were highest in Australia, Canada, Western Europe, Japan, and the United States; the lowest incidences were reflected for the majority of the African continent (except for South Africa), India, the Middle East, and South American countries surrounding the Amazon basin (GLOBOCAN Colorectal Cancer Data, 2008). Notably, colorectal cancer rates stabilized in the US in the mid-1980s, and have steadily declined since (SEER data), especially in distal as compared to proximal cases, likely contributable to positive societal factors such as increased awareness, early detection through endoscopic screening, and advances in preemptive outpatient polyp removal (Umar and Greenwald, 2009). However, influences such as these have not prevented the rapid rise in colorectal cancer observed since 1985 in Japan and the Republic of Korea, with rates now comparable to those of the US and Canada (GLOBOCAN Colorectal Cancer Data, 2008). Largely by virtue of conflict, these two countries were directly influenced by American culture, now apparent in the lives of postwar Japanese and Korean generations. Clearly this form of cancer, in addition to other chronic diseases, is directly associated with acculturation falling under the umbrella of westernized culture. The simple clues to overcoming this caveat can be realized by examining ways in which modern lifestyles and environments have altered human physiology, and how the traditional peoples of the world still practice prevention.

\section{INFLAMMATION, HOMEOSTATIC DISRUPTION, AND CANCER}

In what ways has homeostasis been altered by modern living? Instead of a few minor deviations, humans have both consciously and unknowingly introduced numerous hurdles to maintaining appropriate physiological functioning. The general awareness that a failure to eat right and exercise can lead to poor health is now extensively supported by scientific data demonstrating the molecular and cellular toll of failing to safeguard one's health. The physical body can be thought of as a sophisticated machine that relies on proper fuel, regular flushing, and routine upkeep in order to function at its maximum efficiency. If organisms are largely what they eat, and humans are turning to nutrient-poor, yet toxin-rich food, it is no surprise that signs of wear and fatigue are evident in many populations. Chronic inflammation is recognized or suspected to be an underlying cause of a plethora of modern pathologies, including cardiovascular disease, diabetes, autoimmune disorders, neurological dysfunctions, and cancer. Imbalances on molecular and cellular levels that promote inflammation are numerous and arise predominately from intrinsic factors such as redox fluctuations that evoke free radical damage and stress signaling to resolve acute challenges. Whereas short-term signals are necessary for survival, it is in the case of unresolved insult that the body begins to waste its energy and develop abnormal responses to internal and external triggers, thus gradually promoting susceptibility to chronic diseases such as cancer (Coussens and Werb, 2002).

Humans have the means for controlling inflammation through a number of innate pathways including the cholinergic pathway which strongly influences cytokine production and suppression. Another inherent mechanism for counteracting inflammation is dependent upon vitamin $\mathrm{D}$, a nutrient once obtained in abundance through UV exposure, but now found to be severely lacking in the serum of humans living in developed regions. When obtained at appropriate levels, vitamin $\mathrm{D}$ acts as a prohormone via its nuclear receptor in cooperation with the retinoid $\mathrm{X}$ receptor to bind DNA and modulate anti-inflammatory gene expression. In addition to this and other modern-day nutrient deficiencies, humans in fast-paced and demanding societies now tend to display physical symptoms of prolonged mental and emotional stress, which can induce chronically elevated cortisol, cytokine, and chemokine levels. Although modern living can be mentally rigorous at times, the requirement of physical labor for survival has been nearly eliminated in certain cultures, thereby leading to dramatic reductions in physical energy expenditures. This trend is coupled with unprecedented increases in hyperconcentrated caloric intake from unnaturally dense foods, such as high-fructose corn syrup, that lessen perceptions of satiety after a meal. In addition to being more susceptible to weight gain, a consistently static body is less likely to efficiently circulate oxygen and nutrients as well as filter lymph contents, further emphasizing how modern living has escalated homeostatic imbalance.

While calorically excessive, the westernized diet lacks essential nutrients including vitamins, minerals, and mediators of oxygenation, thereby promoting acidification, hypoxiation, and dehydration of the body. Given that various tissues and fluids must exist within a narrow $\mathrm{pH}$ range in order to function properly, $\mathrm{pH}$ imbalances can contribute to altered homeostasis. Cancer cells and tumor microenvironments are typically within a relatively acidic range due to their preference for anaerobic, lactic acid-generating metabolism. It should be noted that chemotherapy, phototherapy, and even hyperthermia induce tumor acidification, and the spread of melanoma in a mice study was shown to be fostered by an acidic microenvironment (Rofstad et al., 2006). Related to corrupted pH, membrane potential may be altered in certain cells. It has been demonstrated that bioelectrical signaling serves as a regulator of cellular proliferation and differentiation, and it is possible that altered membrane potential can influence ion flux in a way that would allow for preferential uptake or exclusion of compounds by cancer cells (Sundelacruz et al., 2009). Given the amount of sodium present in processed food, it is clear why molecular activities linked to sodium channels are often dysregulated. Furthermore, the estimated fourfold increase in refined sugar intake in the last century has merely provided fuel for glycolysis-addicted cancer cells. When the body is full of solutes and deficient in its intended solvent, cellular osmotic balance is threatened by dehydration. In addition to a lack of water, optimal flushing of waste products from the body has been limited by the switch from whole to processed grains, which eliminated a major source of the fibrous content once consumed by humans. Gut microflora composition is also altered in modern times, as beneficial levels of probiotics intended to aid 
in digestion are depleted by poor diet and excessive antibiotic use. These evidences of recent alterations in human physiology support the idea that environmentally induced imbalances set the stage for cancer and other chronic diseases.

Modern diets contain significantly higher levels of proinflammatory compounds in comparison to the anti-inflammatory nutrients common in the diets of early peoples (Simopoulos, 2008). Considering that Americans have doubled their consumption of meat and dairy in the last century, a disproportionally large intake of animal fat compared to plant fats has occurred. Different lipids have different metabolic functions and the essential fatty acids (FAs) must be obtained via the diet for biosynthesis of other key compounds, some of which have opposing effects on inflammation. The ratio of omega- 6 to omega- 3 unsaturated FA consumption of primitive humans is estimated to have been roughly $1: 1$, with high amounts of anti-inflammatory molecules such as EPA and DHA. Today's omega-6:3 consumption in the average American is estimated to be almost 17:1 (Simopoulos, 2002). This indicates a relatively rapid and dramatic increase in the intake of pro-inflammatory molecules like arachidonic acid, the precursor of prostaglandins and thromboxanes, coupled with a decrease in the intake of vital anti-inflammatory FAs such as alpha-linolenic acid (ALA). Therefore, eicosanoid-controlled mechanisms that accelerate cardiovascular and inflammatory pathologies such as colon cancer are upregulated by the westernized diet.

Fatty acid-induced chronic inflammation combined with DNA methylation is suspected to fuel colon cancer growth as prostaglandin E2 was shown to silence tumor suppressor genes and promote intestinal tumor progression (Xia et al., 2012). The accumulation of excessive body fat from unhealthy sources is further deleterious as visceral adipose tissue can have a direct pro-inflammatory effect on surrounding tissues (Lysaght et al., 2011), and adipose tissue-derived stem cells have been shown to participate in building the breast tumor microenvironment to facilitate growth and metastasis (Muehlberg et al., 2009). Elevated consumption of low-density lipoprotein (LDL) has a direct inflammatory effect on LDL receptor-expressing cells, and an altered distribution of cholesterol and sphingolipids within the plasma membrane can drastically influence a cell's response to its environment via lipid signaling. Levels of inflammatory enzymes such as cyclooxygenase-2 (COX-2) and inducible nitric oxide synthase (iNOS) are also likely to be upregulated in individuals adhering to the western diet, as well as levels of inflammatory cytokines such as IL- 6 and TNF- $\alpha$. Altered cell signaling involving the EGFRassociated Ras/Raf and PI3K/Akt pathways can be induced via inflammation, and constitutive activation of these cascades is common in GI cancers (Risio, 2011). The introduction and perpetuation of these complex arrays of cellular imbalances can manifest into chronic disease when left unchecked. This effect can occur within a short span of time, as immigrants who adopt a western lifestyle soon acquire increased colorectal cancer risk.

Factors that interfere with homeostasis by creating physiological instability are most apparent at the cellular and subcellular level, but are likely influential on the most basic, quantum interactions that drive the atomic and molecular bonding crucial for cellular functions. Chronic inflammation can lead to nucleic acid damage, lipid peroxidation, protein misfolding and accumulation, prolonged heat shock induction, excessive growth factor secretion, and unnecessary immune activation or subversion. The later effects may be mediated by perturbations in regulatory T-cell numbers and functions, which are now suspected to play an important role in the developing epidemic of allergic, autoimmune, and inflammatory conditions (Fazekas de St Groth, 2012). Unresolved inflammation has numerous tumor-promoting effects (Mantovani et al., 2008), and is an underlying factor behind the fatigue and debilitating pain plaguing millions of otherwise healthy people. However, inflammation is a vital component of normal pathways that initiate immune responses, wound healing, and apoptosis in severely damaged cells. Therefore, acute inflammatory responses, much like acute stress, are beneficial for an organism's survival by inducing a swift and potent response to cellular changes, but chronic conditions can lead to a perpetual state of perceived wound healing. Inflammation is thoroughly involved in all steps of carcinogenesis including initiation via genetic and epigenetic gene expression changes, progression promoted by aberrant cell signaling, and creation of the local and distant tumor microenvironments (Coussens and Werb, 2002). It is now thought that these processes are occurring within a specific cell type, known as a cancer initiating cell or cancer stem cell (CSC). This unique cellular niche retains key stem-like properties allowing it to be responsible for driving tumorigenesis in the same way that it would otherwise drive wound healing and tissue regeneration. Given that embryonic and adult stem cells appear to perform a range of roles, from therapeutic to pathological, it can be argued that local and systemic environments determine these roles by checking and balancing or dysregulating their behavior.

In an attempt to repair prolonged cellular damage, proliferative fibroblasts promote local fibrosis and scarring, and angiogenesis occurs to increase delivery of wound healing mediators. All the while, circulating cytokines and chemokines may sustain a chronic inflammatory state by inducing excessive neutrophilic actions that cause further free radical damage. Tissue-derived and mesenchymal stem cells are intimately involved in the repair and regeneration of inflamed tissue. Homeostasis of the intestinal epithelium, the majority of which gets replaced weekly, is maintained by stem cells residing within crypt bases that respond to cues from the microenvironment such as morphogenetic signaling through Wnt, Notch, Hedgehog, and BMP (Medema and Vermeulen, 2011). Three stem cell compartments exist within the human colon: crypt epithelial stem cells, subepithelial stem cells which include pericryptic myofibroblasts, and immigrating mesenchymal stem cells. These specialized stem cell niches interact to orchestrate epithelial cell differentiation, renewal of the colonic mucosa, and chronic inflammatory responses underlying colorectal oncogenesis (Sipos et al., 2012). One major genetic instability often linked to the initiation of colon cancer is chromosome $1 \mathrm{p}$ deletion, which otherwise encodes the glutathione- $S$-transferases and other enzymes involved in detoxification, as well as numerous tumor suppressors, DNA repair, and checkpoint genes vital for preventing malignancy (Payne et al., 2011). Studies in human GI cancers and rodent models indicate that loss of heterozygosity of the Adenomatous polyposis coli (APC) gene is associated with early tumorigenesis. It was found that silencing of this tumor suppressor could occur in the absence of mutation or a gain or loss of 
genetic material, providing evidence that epigenetic regulation is involved (Amos-Landgraf et al., 2012).

As we will discuss, cellular alterations arising from complex epigenetic changes are an important level of gene expression regulation beyond DNA mutation and are highly pertinent to cancer causation and its prevention. Silencing of critical tumor suppressor functions along with gains in oncogenic expression can be transformative in a long-lived stem cell that has already acquired various mutagenetic and epigenetic changes, or could lead to plasticity within a terminally differentiated cell causing it to reacquire stem-like properties and transform (Rapp et al., 2008). Extrinsic or innately driven accumulation of chromosomal instabilities within a stem cell can allow for unchecked clonal expansion of this cell and its progenitors into CSCs. These transformed stem-like cells then build and recruit a protective niche of heterogeneous tumor tissue and stroma where they can remain highly functional, relatively quiescent, treatment-resistant, and poised to migrate if surgically disturbed. CSCs can also facilitate the epithelial-to-mesenchymal transition (EMT) and migrate along the SDF-1/CXCR4 chemotaxis pathway, which is implicated in angiogenesis and metastasis (Liekens et al., 2010).

With these considerations, it is clear that correlations exist between modernization, acculturation, and increased risk for chronic diseases such as colorectal cancer, which is now the third leading cause of all deaths in industrialized countries (Barone et al., 2011). According to GLOBOCAN worldwide data, the three cultures with the lowest cancer rates (East Mediterranean, African, and Indian) interestingly consume the most potently antiinflammatory, plant-based diets in the world, while maintaining adherence to their traditional ways of life. Currently, one in three Americans contracts cancer and one in four American deaths is cancer related (National Cancer Institute, 2005). The steady rise in life expectancy previously observed within the US population is now forecasted to begin declining (Olshansky et al., 2005), suggesting that for the first time in centuries, American children will not live as long as their parents. Therefore, for the sake of posterity, it is time to acknowledge and address risk factors arising from our daily habits and living environments in order to reverse rising global trends in chronic disease. Explicit links between environmental exposures and cancer have already been made in the case of ionizing radiation and asbestos, and other parallels remain to be found within the ranks of the 80,000 chemicals currently registered with the US EPA, the vast majority of which remain untested.

Given that health challenges such as infection, injury, and childbirth are medically manageable in modern times, the average life expectancy has increased greatly. Since aging cells are more prone to oncogenesis, it could be argued that the observed trends in cancer rates are due to the simple fact that humans are living long enough to contract it (Dunn, 2012). Age is a considerable risk factor, but it does not account for incidences in young and otherwise "healthy" individuals such as those contributing to the rising rates of Acute Lymphoblastic Leukemia (ALL) and brain cancer in children in recent decades. Considering that certain early cultures did enjoy a longer lifespan, age would have been a risk factor then as well, in addition to mutation through inheritance or opportunistic infection. Cancer in antiquity did exist, as bone malignancies have now been identified in mummified remains, although at a $0 \%$ rate in samples from children and a 1.2\% rate in adult specimens (Zink et al., 1999). It must be noted that this analysis did not account for cancer in non-osseous locations, so overall cancer rates in ancient Egyptians were surely higher, but still only a fraction of the $33 \%$ cancer incidence rate for present-day Americans.

In spite of limited historical records and pathological evidence, it is generally thought that the occurrence of malignancy was remarkably low in ancient times compared to modern times, suggesting a role for present-day environmental exposures (David and Zimmerman, 2010). Also rising are incidences of cancer in uncommon locations, such as the esophageal-gastric junction and the salivary gland, with trends currently unaccounted for (Zheng et al., 1997). It should be acknowledged that the number of cancer related deaths in the US is on the decline due to significant advances in oncology. However, in spite of our medically progressive society, cancers induced by poor diet and lack of exercise are still causing one third of all preventable deaths, with another proportion attributable to tobacco and alcohol use (American Cancer Society, 2012). A big-picture analysis reveals that homeostasis has largely been redefined by the abrupt changes in daily habits such as low phytochemical intake, electromagnetic field (EMF) exposure, and toxin accumulation largely absent from human existence until recent times. These factors now constitute the unintended health and environmental legacy of westernization, with health impacts arising on a global scale that may have serious implications for adaptation in the modern world.

\section{LOW-LEVEL ENVIRONMENTAL EXPOSURES}

According to a recent report from the President's Cancer Panel, the vast majority of cancers arise from environmental factors, directing attention to the fact that toxins play a significant, yet unappreciated role in carcinogenesis and the lives of Americans (National Cancer Institute: President's Cancer Panel, 2009). There are many types of common environmental and physiological contaminants including heavy metals, radioactive isotopes, industrial solvents, agricultural chemicals, petroleum byproducts, and plastic components, some of which are classified as endocrine disrupting compounds (EDCs). The endocrine system is comprised of a network of vital chemical messengers (hormones) and cellular targets that together orchestrate homeostasis in liaison with the nervous system. Many environmental EDCs such as BPA, diethyl hexyl phthalate (DEHP), and the parabens act as xenoestrogens. Thus, these compounds are capable of exerting potent hormonal disruption via the estrogen receptors (ERs), which are fairly promiscuous in ligand binding, and mediate non-genomic and genomic signaling via presence in multiple cellular locations. The mechanisms allowing EDCs to influence estrogenic signaling arise from direct ER interactions, as well as indirectly through metabolic enzymes involved in estrogen synthesis, such as aromatase (ARO), and transcription factors like the aryl hydrocarbon receptor (AhR; Shanle and $\mathrm{Xu}, 2011)$.

Endocrine disrupting compounds may also exert their effects by acting as anti-androgens or interfering with the hypothalamicpituitary-adrenal axis and/or thyroid gland functioning, the later shown to be the case for triclosan, the active ingredient in most antibacterial soaps (Dann and Hontela, 2011). Xenohormones can induce changes in estrogen- and androgen-responsive tissues 
including the developing breasts, ovaries, prostate, and testis; it is noteworthy that prostate and breast cancer are predicted to be the most common non-skin cancers diagnosed in 2012 according to the NCI, having now advanced past lung cancer. The increase in breast cancer incidence is not restricted to women, as cases in men are becoming more frequent. An alarming trend in early maturation of young females is also occurring. A recent study found the proportion of girls with breast development at age eight to be higher than reports from 10 - to 30 -years ago; $18 \%$ of white, $43 \%$ of black, and $31 \%$ of Hispanic girls evaluated had undergone the onset of puberty by 8 years old (Biro et al., 2010). Therefore, when present in utero and during early reproductive development, low levels of EDCs may contribute to or counteract endogenous hormone production and xenoestrogen exposure is likely capable of promoting feminine phenotypes.

Xenoestrogens are present in an overabundance of products that American consumers use frequently. BPA is found in polycarbonate plastics, metal can linings, dental sealants, epoxy resins, and register receipts. This chemical appears to be strongly linked to premature puberty in females, the induction of male infertility, and spontaneous miscarriage due to its hormonal, mutagenic, and genotoxic activities (Tiwari et al., 2012). DEHP is one of the many plasticizers used to soften polyvinyl chloride (PVC) during manufacturing and may constitute a large percentage of a final product's weight, from which it actively leaches out upon hydrolysis, heat, and/or pressure. PVC plastic and phthalates are used in a wide array of products making them nearly ubiquitous in our lives in the form of plumbing pipes, electrical cords, food packaging, vinyl floors, faux leather handbags, cosmetics, infant chew rings, as well as medical catheters, blood bags, and tubes. Given the prevalence of plastic in healthcare, indirect accumulation of EDCs within the body can be a side-effect of hospitalization, and detoxification of medical settings should become a priority of administrators, as medical care should not contribute to the causes of disease (Ruzickova et al., 2004). Accountability within product manufacturing is highly urged, as xenoestrogens like the parabens should not be included in infant shampoo formulations, and PVC, which may also contain stabilizers such as lead and cadmium, should not be present in children's toys. The common household and food service industry practices of freezing, microwaving, and storing food in plastic can serve to accelerate leaching of harmful components. Furthermore, burning or disposing of plastic waste in landfills directly releases toxins into the air, soil, and groundwater. Plastics are petroleum byproduct-based, thus contaminants linked to petroleum acquisition and separation also find their way into cheap consumer products, the demand of which further stimulates the toxic effects of the oil industry.

Given that expression of ERs occurs in numerous cell types, with an increase in estrogen-responsive genes often found in colorectal cancers, the effects of these compounds in the GI tract are under investigation. DEHP was shown to stimulate expression of the multi-drug resistance transporter (MDR1) gene in colon cancer cells by binding to the steroid and xenobiotic receptor (SXR; Takeshita et al., 2006). Animal studies exploring the effects of BPA found it to be present in the small intestine almost immediately following oral ingestion, with evidence that it was reabsorbed into the colon (Sakamoto et al., 2002). Perinatal exposure of BPA at human reference doses was shown to alter intestinal barrier dynamics, influence GI pain reflexes, and induce a potent inflammatory response in adult female offspring (Braniste et al., 2010). The effects of BPA and other xenoestrogens have been more extensively investigated in breast tissue, in which cellular activity is tightly regulated by the presence of ERs, so the relevancy of these studies may extend to ER expression in colon cancer. Whereas the growth-promoting $\mathrm{ER} \alpha$ isoform tends to be upregulated in hormonally responsive breast cancers, the ER $\beta$ isoform, which likely serves a tumor suppressor role, is downregulated via a variety of mechanisms (Fox et al., 2008). It is possible that xenoestrogen exposure early in development primes breast tissue for chemically induced cancer not only in females, but also in males, and may set determinants in utero for other chronic inflammatory diseases.

Pre-pubertal exposure of BPA in rodent mammary tissue was shown to upregulate expression of steroid receptor coactivators (SRCs), ER $\alpha, E G F R$, and phospho-IGF-1R, leading to activation of downstream kinases including ERK and Akt (Lamartiniere et al., 2011). Xenoestrogenic compounds at humanly bioactive doses have been shown to exert pro-tumorigenic epigenetic changes in breast epithelial cells through repression of miRNA-9-3 (Hsu et al., 2009), increased expression of the histone methyltransferase EZH2 upon in utero exposure (Doherty et al., 2010) and silencing of the LAMP3 gene (Weng et al., 2010). The proliferation of many cell types, including adipocytes, is accelerated by certain xenoestrogens which have been described as "obesogenic" because they promote obesity via numerous mechanisms including the reduction of basal metabolic levels and increased appetite stimulation (Grun, 2010). BPA and other EDCs have been linked to aberrant genetic programming during fetal development that likely increases susceptibility for adult obesity, arguing that modern trends in unusually large infant and adolescent body sizes may also be partly attributable to early EDC exposure (Vom Saal et al., 2012). Attention should be given to the fact that BPA levels are detectable in over $90 \%$ of individuals tested (Lamartiniere et al., 2011), along with a slew of other EDCs such as the parabens, which were found to be present in $99 \%$ of breast tissue samples in a study of mastectomy patients (Barr et al., 2012).

Aside from a direct role in carcinogenesis, EDCs are capable of influencing the seat of homeostatic control, the nervous system. Exposure to these compounds carries possible repercussions for sex differences in the developing brain through abnormal hormonal influences such as altered estrogen to androgen ratios and thyroid levels. In one human study, reduced masculine play was observed in a group of school-aged boys with higher levels of certain phthalates present in their systems in comparison to boys with low levels of these compounds (Swan et al., 2010). Animal studies have revealed that gestational exposure to BPA can alter social behavior in juvenile and adult mice, with higher mRNA levels of the glutamate transporter Slclal in the brains of females. To support the role of BPA in epigenetic regulation, this same study found altered expression of the DNA methyltransferase (DNMT) genes Dnmt1 and Dnmt3a in the brains of mice exposed in utero (Wolstenholme et al., 2011). Cholinergic signaling in the brain was found to be altered in mice after a single dose of BPA at 10 days 
old, which manifested in changes in spontaneous behavior, lowered adaptation to new environments, hyperactivity, and reduced nicotine sensitivity in adulthood (Viberg et al., 2011). In addition, BPA demonstrated the ability to enhance spinogenesis in adult hippocampal neurons, with rapid effects observed for nanomolar doses, indicating large responses from small amounts (Tanabe et al., 2012). Considering the rapid rise in childhood and adult ADHD, coupled with the alarming $26 \%$ climb in autism-spectrum disorders within just a 2-year span (2006-2008; CDC, 2012), it is clear that modern environmental factors are affecting cognition in a significant manner.

Endocrine disrupting compounds-induced hormonal imbalances can also have drastic effects on reproductive organs. Studies by one group in male rats exposed neonatally to BPA revealed reduced spermatogenesis through downregulation of cell junctional proteins (Salian et al., 2009b), in addition to reduced fertility in subsequent generations, demonstrating vertical transmission of exposure-related effects (Salian et al., 2009a). Male sexual differentiation disorders, such as hypospadias, have increased in recent decades and it is likely that the accompanying increases in xenoestrogen and/or anti-androgen exposures are a factor (Sultan et al., 2001). Altered expression of $\operatorname{ER} \alpha$ and $\operatorname{ER} \beta$ in the testis of adult rats subjected in utero to BPA was shown to correlate with DNA hypermethylation of both promoters, accompanied by upregulation of Dnmt3a and Dnmt3b expression (Doshi et al., 2011). This suggests that EDCs can produce epigenetic feedback loops to autoregulate their target cellular receptors. It is sobering to consider the mixtures of these epigenetically active chemicals that likely circulate now within the majority of people in developed regions. A recent analysis of umbilical cord blood content from ten minority newborn babies indicated detectable levels of 232 environmental contaminants, including BPA (90\% of samples tested), DEHP, fire retardants, polycyclic musks, rocket fuel, and banned pesticides; all present at the time of birth. To date, a total of 414 chemicals have been detected in 186 people during the course of testing and constitute what the Environmental Working Group (EWG) has termed, "the human toxome." The CDC has conducted its own nationwide biomonitoring program over the last decade and was reported to have detected 203 chemicals distributed among the thousands of individuals tested (Environmental Working Group, 2009, Pollution in People Report).

Other persistent organic pollutants (POPs), such as dioxins, polychlorinated biphenyls (PCBs), organochlorine pesticides like DDT (banned in the US in 1972), and polybrominated diphenyl ethers (PBDEs) are exhibiting a "boomerang" effect within the food chain. Over the course of decades, it is possible for a compound to travel thousands of miles and transfer from smaller to larger predators, until finding its way onto a plate in the form of meat, dairy, or seafood like tuna and mackerel. Upon ingestion, these long-lived, lipophilic molecules integrate into adipose tissue. We absorb the majority of toxins through food, with common culprits including processed meats containing carcinogenic preservatives, items stored in BPA-lined cans, and soft drinks and deserts containing high levels of artificial ingredients. Even fresh produce can carry large toxin loads from conventional chemical-based farming practices, with tests showing apples carried combinations of 57 chemicals and a single celery sample contained 14 pesticide residues (Environmental Working Group, 2011, Pesticides in Produce Report from 2000 to 2009 USDA and FDA data).

Common herbicides and pesticides can induce potent cellular changes, and atrazine was shown to stimulate growth in normal colonic epithelial cells, as well as colon cancer cells, with the highest proliferative effects notably observed for lower doses (Greenman et al., 1997). Atrazine is the most commonly used herbicide in the US with $75 \%$ of all cornfields treated each year, making it a prevalent contaminant of ground and drinking water. Epidemiological studies revealed that atrazine exposure in women living in farming communities was linked to increased menstrual cycle irregularities and altered reproductive hormone levels; notably, this effect was observed at levels below the US EPA's maximum contaminant level (Cragin et al., 2011). In addition, gender influences have been observed in wildlife exposed to atrazine, apparent by partial or complete feminization of male fish, amphibians, and reptiles; the effects of which are statistically significant and consistent across vertebrate classes (Hayes et al., 2011). Atrazine has been shown to exert hormonal changes at low, ecologically relevant doses in adult male African clawed frogs through demasculinization, leading to the ability to produce viable eggs. Therefore, not only do EDCs have implications for human health, they also threaten lower order species, likely contributing to global declines in amphibian populations (Hayes et al., 2010).

The modern methods by which food is prepared and served have also introduced toxic chemicals into the body. Perfluorinated compounds (PFCs), including perfluorooctanoate (PFOA) and perfluorooctane sulfonate (PFOS), are components of nonstick cooking surfaces as well as stain and water-repellant food packaging and fabric coatings. PFCs are known peroxisome proliferators and hepatocarcinogens, and have been shown to alter membrane potential and intracellular $\mathrm{pH}$ in colon cancer cells, based on the hydrophobicity of the compound (Kleszczynski and Skladanowski, 2009). In a study of PFOA effects in the F344 rat liver, this chemical was shown to inhibit gap-junctional intercellular communication which serves as an epigenetic marker of tumorigenesis, in an ERK and PC-PLC-dependent manner (Upham et al., 2009). In human liver cells, PFOA upregulated transcription of the de novo DNA methylator, Dnmt3a, leading to hypermethylation of the glutathione-S-transferase Pi (GSTP) promoter, which could serve to limit the tumor-suppressive role of GST during detoxification (Tian et al., 2012). Alteration of GSTP methylation was also observed in rat livers following prenatal exposure to PFOS (Wan et al., 2010), further emphasizing the epigenetic capabilities of common chemicals.

It has also been suggested that PFCs suppress cytokine secretion by immune cells via alteration of NF- $\kappa$ B activity, and PFOA was shown to be the least active of all PFCs assessed (Corsini et al., 2012). A prospective study of a birth cohort from a Faroe Island hospital revealed that high concentrations of PFCs in maternal pregnancy serum and child serum were associated with severely reduced levels of diphtheria and tetanus antibodies in vaccinated children at the ages of five and seven. These results could have implications for the development of humoral immunity and effectiveness of childhood vaccines (Grandjean et al., 2012). BPA exposure is also implicated in aberrant immunity, as exposed B1 cells 
were shown to upregulate autoantibody production in vitro and in vivo, with upregulated ER expression in $\mathrm{B} 1$ cells from aging mice that had developed lupus (Yurino et al., 2004). Like BPA, neonatal exposure to PFOS and PFOA has been shown to induce neurobehavioral issues in mice via cholinergic signaling, with symptoms worsening with age (Johansson et al., 2008), and this effect may have implications for this pathway in inflammation and cancer. Cholinergic pathways are also involved in the neurotoxic mechanism of the commonly used insect repellant, DEET, which has also been shown inhibit cholinesterases, leading to acetylcholine excess within synapses (Corbel et al., 2009).

Compounds consisting of highly electronegative atoms, such as fluorine, are adept at stealing electrons from cellular structures and may participate in forming reactive species such as the hypochlorous radical in the case of chlorine. While they do afford convenience and functionality, these products have long half-lives within the environment and body, making them damaging not only the consumer, but to the workers manufacturing them and residents of the surrounding towns. In fact, one epidemiological study with large sample sizes found that people living near a PFC-producing plant in West Virginia had a sevenfold increase in PFOA blood levels as compared to the US average. Children living in this community were exposed to the chemical likely in utero or via drinking water and breast milk, and had 44 and $42 \%$ more PFOA and PFOS, respectively, in their systems than their mothers. These results demonstrate the enhanced vulnerability of the young to toxin accumulation, and suggest that markers of early exposure events can persist for decades (Mondal et al., 2012). The protective blood-brain barrier is not present in utero and the placenta is not a superb shield against a mother's circulating metabolome, therefore the rapidly developing fetus is highly vulnerable to chemical exposure, of which can lead to irreversible neurological and organ insult (Grandjean and Heindel, 2008). Given that the body has not evolved to degrade and clear this type of molecule, exposure to chemicals such as PFCs is suspected to lead to dysfunction of the kidneys and liver, which are vital for maintaining homeostasis.

These findings argue that humans in certain societies undergo a lifelong bioaccumulation of toxins from conception, through major developmental stages and into adulthood. There is a growing body of evidence for fetal origins of adult disease, and the data presented here implies that epigenetic programming within stem cells during key prenatal and neonatal stages is influenced greatly by environmental toxin exposure. A growing child experiences a crucial phase of developmental plasticity in which epigenetic marks are made in response to dynamic environmental changes that will ultimately manifest during transition phases later in life (Hochberg et al., 2011). Animal studies have emphasized the influence of epigenetics on phenotype; for example, perinatal exposure of yellow agouti mice to BPA at humanly relevant doses was found to induce global gene methylation changes capable of altering coat color distribution in the offspring (Anderson et al., 2012). Direct correlations have been made between urinary levels of BPA in humans and the development of avoidable medical disorders and morbidity (Lang et al., 2008). An a large study of a representative sample of American adolescents and adults, a significant relationship was found between urinary phthalate and BPA metabolite concentrations and altered thyroid levels, demonstrating that adverse effects due to EDCs are already measurable in the US population (Meeker and Ferguson, 2011).

Therefore, women with child-bearing abilities exert dramatic influences on the health, wellbeing, and reproductive capabilities of future generations on levels previously unrecognized. By crossing the placenta during pregnancy and into breast milk during lactation, these compounds are contaminating what should be the purest of physiological environments. Not meant to be taken as hyperbole, isolated and moderate contact with these compounds is unlikely to be a cause for concern, but daily low-dose exposures may carry subtle, yet severe implications in the form of hermetic responses. Given that a range of exposures can occur for one individual, including heavy metals like lead and mercury, common carcinogens such as formaldehyde and benzene, electromagnetic radiation from wireless communications, and pharmaceutical drugs (which can be present in drinking water), the human body is facing an unprecedented level of adverse and potentially synergistic effects. If the environment we live in is admittedly polluted with changes already apparent in marine life and lower order mammals, what natural defenses exist within our cells to ensure optimum functioning in this time of modern genetic pressure? Prevention through primitive plant and human adaptations may be the intended route for counteracting and reversing the imbalances we have postulated to lead to chronic disease. Presented in Table 1 is an overview of common endogenous compounds of both synthetic and natural origin theorized to play a role in human homeostasis, or the disruption thereof.

\section{PHYTOCHEMICAL DEPLETION}

The designation of "cancer" was first used by Hippocrates in reference to the crab-like appearance of certain tumors. Known as the father of Western medicine, he also coined the phrase, "let food be thy medicine, and medicine be thy food," demonstrating his respect for the relationship of diet to human health. As opposed to the chemical cocktails that co-emerged with modernization and now exist within humans, it is equally relevant to consider the compounds now physiologically absent that were once components of human diets. Plant-eating organisms have acquired sophisticated adaptations to use phytochemicals, some of which are shown in Figure 1, as defense against a wide variety of threats, ranging from microbial infection to cancer. If plant compounds are protective and cancer is common in phytochemical-deprived societies, then in one sense, cancer can be approached as a deficiency disease, reminiscent of what G. Edward Griffin proposed in his book World Without Cancer (Griffin, 1974). It is acknowledged that the body does not operate properly without recognized nutrients such as Vitamin C, B12, and B6, much less the complex array of obscure phytonutrients once obtained by humans living in tropical and temperate regions. Epidemiological data collected from underdeveloped regions has drawn links between primitive diets and comparatively low risk for common cancers, and may explain the elevated longevity enjoyed in certain geographic locations. It is also instructive to review published studies on the composition of paleolithic diets versus that of modern diets; the depletion of plant-based compounds is striking.

Plants are recognized and proposed to have a wide molecular basis of preventive mechanisms. Many contain compounds that 


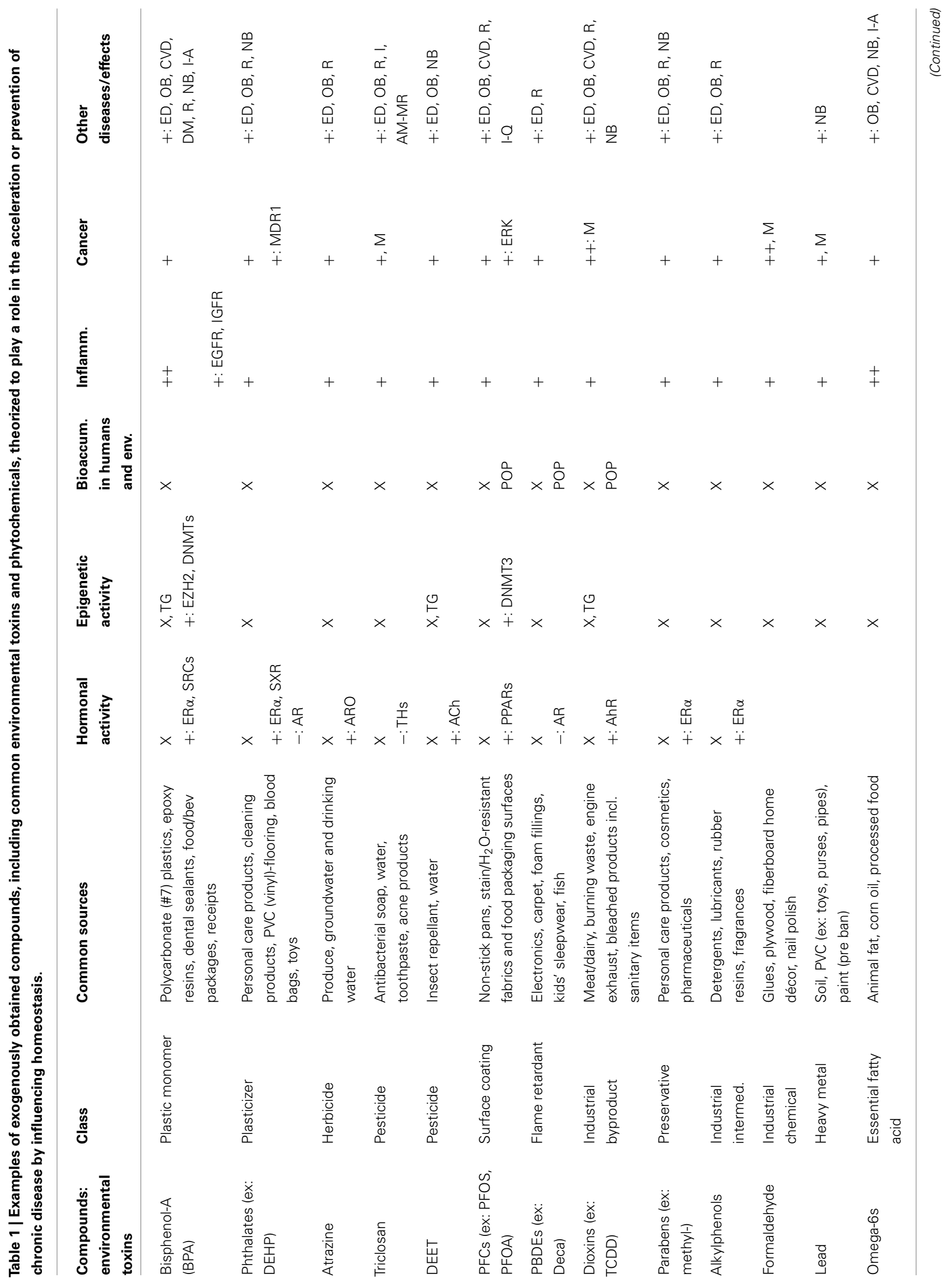




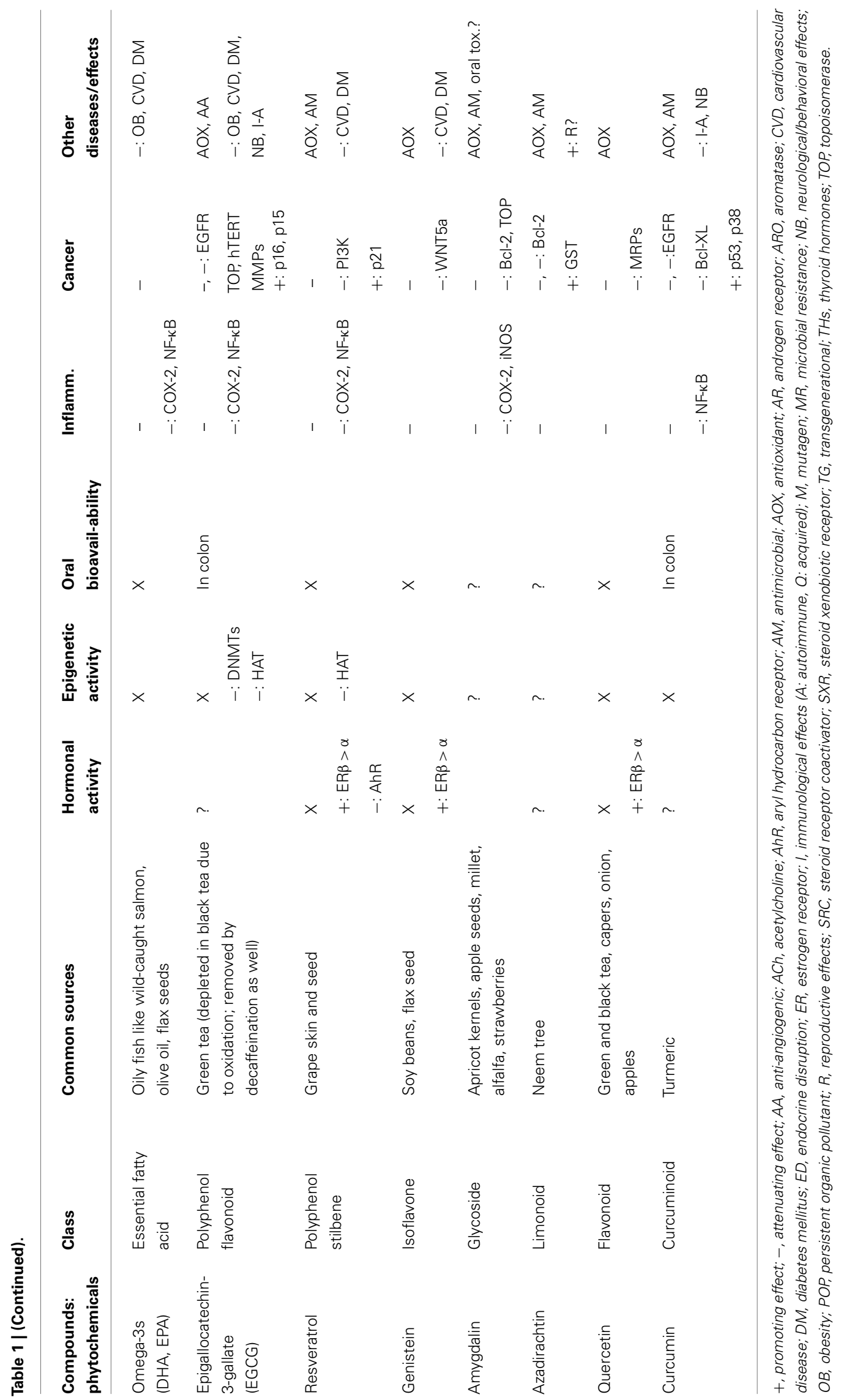




\section{Azadirachtin}

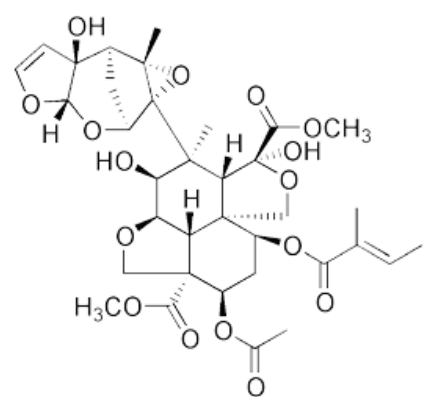

Amygdalin

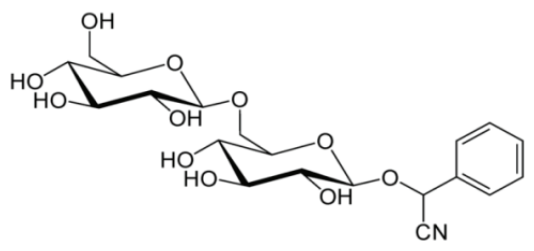

Curcumin<smiles>COc1cc(/C=C/C(=O)/C=C/c2ccc(O)c(OC)c2)ccc1O</smiles>

\section{Epigallocatechin-3-gallate}<smiles>O=C(O[C@H]1Cc2c(O)cc(O)cc2O[C@H]1c1cc(O)c(O)c(O)c1)c1cc(O)c(O)c(O)c1</smiles>

Rosmarinic Acid<smiles>CC(C)CCCCCCCCCCCCCC(=O)OC(Cc1ccc(O)c(O)c1)C(=O)O</smiles>

Capsaicin

Lycopene<smiles>CC(C)=CCC/C(C)=C/C=C/C(C)=C/C=C/C(C)=C/C=C/C=C(C)/C=C/C=C(C)/C=C/C=C(\C)CCC=C(C)C</smiles>

FIGURE 1 | Structural examples of phytochemicals with known or suspected medicinal properties such as antioxidant, antimicrobial, anti-inflammatory, and anti-cancer activity, likely stemming from protective and defensive roles in their plant sources.

act as direct or indirect antioxidants, participate in detoxification and elimination of waste, activate regulatory T-cell responses, and modulate cell signaling to induce apoptosis in damaged cells while promoting differentiation in others. Ingestion of certain fruits and vegetables can promote balanced $\mathrm{pH}$ levels by alkalinizing the blood and tissues via their high mineral and chlorophyll content. Weak acids from citrus juices and plant vinegars can also buffer $\mathrm{pH}$ through conversion to strong bases during metabolism, as in the case of citric acid and acetic acid. It should be noted that many fruits contain high sugar content, which could feed cancer cell metabolism. However, given that cancer cells will preferentially overexpress certain glycolytic enzymes, it is possible to exploit the Warburg effect to identify new metabolic targets in malignancy (Resendis-Antonio et al., 2010). Invasive tumors from human breast and colon tissues have been reported to upregulate an array of enzymes, including glycosidases, in comparison to normal cells (Bosmann and Hall, 1974). It is interesting to note that plants produce glycosidic compounds only broken down in the presence of certain enzymes, suggesting that they may act on Trojan horse principles. By increasing its uptake of sugar-containing compounds, a cancer cell can inadvertently bring in attached cytotoxic groups such as cyanide $(\mathrm{CN})$. $\mathrm{CN}$-containing glycosides and nitrilosides exist in thousands of plants including strawberries, alfalfa sprouts, spinach, pecans, and in particularly high concentration in apricot kernels and other seeds, thus responsible for their characteristically bitter taste. It should be noted that bitterness is an important sensory indicator of potently anti-inflammatory, yet potentially poisonous compounds (in excessive amounts) within a plant. In medicinal chemistry, there is little distinction between a drug and poison, and the specific poisoning of cancer cells is also the basis of chemotherapy.

In one study, six bioactive compounds extracted from peach seeds, including amygdalin, showed marked antitumor activity, two of which were as effective as the green tea (GT) polyphenol 
EGCG. More importantly, the most potent compounds contained a carboxyl group or hydrogen instead of $\mathrm{CN}$, thereby demonstrating that glycosidic compounds can exist without the threat of presumed toxicity (Fukuda et al., 2003). The reported historical use of apricot kernel extract for pain reduction and inflammation was investigated in lipopolysaccharide-exposed mouse microglial cells, and results revealed an anti-inflammatory effect likely mediated through suppression of COX-2 and iNOS expression (Chang et al., 2005). Amygdalin also induced apoptosis in DU145 and LNCaP prostate cancer cells through caspase- 3 activation, involving the downregulation of Bcl-2 and upregulation of Bax (Chang et al., 2006b). Another study revealed that amygdalin treatment lead to decreased expression of exonuclease-I and topoisomeraseI in SNU-C4 colon cancer cells, demonstrating that this compound can induce cell cycle arrest in malignant cells (Park et al., 2005). Amygdalin and other glycosidic compounds were abundant in the diets of early humans, and are commonly eaten by animals in the wild; the dietary lack thereof may contribute to increased cancer rates observed not only in humans, but also domesticated animals.

Another recent discovery has suggested that plant microRNAs (miRNAs) can play a protective cellular role by participating in a unique form of interspecies signal transduction. Secreted vesicles containing exogenous miRNAs can accumulate to measurable levels in the plasma of humans upon oral ingestion of rice. It has been shown that these intact RNAs are absorbed through the GI tract into the blood stream where they specifically bind to mammalian receptors, such as the LDL receptor adaptor protein 1 (LDLRAP1; Zhang et al., 2012b). There is also evidence that peptides from terrestrial and marine plant are antineoplastic, antifungal, antibacterial, antiplatelet, and antimalarial, along with the benefits of displaying little antigenicity, low-molecular weight, and easy absorption (Tan and Zhou, 2006). Rare cyclic peptide conformations exist within plants that offer greatly enhanced stability and bioavailability over the linear peptides found in mammals. Cyclopentapeptides obtained from the root of the Aster tataricus plant were shown to have in vivo antitumor effects, and synthesized cyclic astins were able to induce caspase-mediated apoptosis in a human papillary thyroid carcinoma cell line (Cozzolino et al., 2005). How this and other anti-cancer mechanisms serve a defensive role in plants is up for debate, and whether they originated in an extremely early common ancestor or were the result of extensive human and plant adaptation is also not clear.

The plant likely produces these secondary metabolites in place of an adaptive immune response to promote its own defense against DNA damage and unwanted foreign growth. This may be why extracts of certain plants such as neem (Azadirachta indica), tea tree (Melaleuca alternifolia), and rosemary (Rosmarinus officinalis) are able to exhibit such broad spectrum inhibition of microorganisms and high degrees of predator deterrence via adverse sensory and metabolic reactions. Volatile plant compounds may also defend against predation through interference with insect and mammalian reproductive efficiency. Neem extract was shown to be larvicidal against mosquitoes (Dua et al., 2009), found to inhibit early stages of rodent embryogenesis and implantation (Mukherjee et al., 1999), and has been historically used as a human contraceptive in India. These proposed repressive effects on embryogenesis could also influence the mechanisms allowing for trophoblastic-like growth of invading tumors and CSCs. Aside from these implications, neem extract has been demonstrated to be gastroprotective by limiting hyperacidity and ulcer development in vivo (Maity et al., 2009), shown to be potently anti-mutagenic in chemically exposed fish (Farah et al., 2006), and acted as an oral chemopreventive agent by stimulating phase II detoxifying enzymes in a model of hamster buccal pouch carcinogenesis (Subapriya et al., 2005). These preliminary studies demonstrate the diverse medicinal mechanisms remaining to be characterized for the plant known in ancient times as Sarva Roga Nivarini, or "curer of all ailments.”

The optimum acquisition of secondary metabolites from plants depends upon growth conditions, similar to the way that human phenotype is largely dependent upon environment. Phytochemical levels tend to be higher when harvest occurs during the early morning hours surrounding sunrise or when an impending threat has been detected, as in the case of increased quercetin and diallyl sulfide levels following the crushing of a garlic bulb. The region of the plant from which the highest levels of nutrients can be extracted is also variable. Typically, the colorful outer peels of fruits carry significant levels of protective and defensive compounds for counteracting UV light and pathogens. High concentrations of beneficial compounds are also found in seeds, kernels, and sprouts in order to ensure survival of the plant's genetic material and developing seedling. Research is currently exploring the effects of exogenous compounds on plant metabolite production. In one study, an analysis of dried samples from tomatoes grown in the US during a 10 -year period found that organic tomatoes contained on average $79 \%$ more quercetin and $97 \%$ more kaempferol when compared to conventionally grown samples (Mitchell et al., 2007). However, an Italian study found that organically grown tomatoes contained more salicylic acid, but less lycopene and vitamin C, in addition to higher cadmium and lead when compared to the conventionally grown group (Rossi et al., 2008). Even different cultivars of grapes raised in controlled agronomic environments were shown to differ in their flavonol content. When tested on Caco-2 colon cancer cells, each of the three extracts were effective at limiting growth and inducing apoptosis, but evoked different responses at lower doses, demonstrating that chemopreventive properties can vary with cultivation (Dinicola et al., 2010). It would be interesting to explore whether or not modern agricultural practices have induced epigenetic changes within the plant genome beyond the genetic modifications already intentionally introduced, and how this affects medicinal properties.

Grape skin and seed contain resveratrol, which has been shown to have many chemopreventive properties by protecting colon cells from chemotherapy-induced cytotoxicity (Cheah et al., 2009) and potentiating colon cancer cell apoptosis (Radhakrishnan et al., 2011). Resveratrol demonstrated an anti-inflammatory effect in a model of experimental colitis by rebalancing redox status, downregulating adhesion molecules, and limiting immune cell invasion (Abdallah and Ismael, 2011). This compound was also shown to mediate anti-inflammatory actions through reduced NF- $\kappa$ B activation upon LPS treatment of human colon cancer cells (Panaro et al., 2012). Dietary-feeding of grape seed extract (GSE) in azoxymethane-treated F344 rats was able to prevent aberrant crypt foci formation likely via suppression of $\beta$-catenin, NF- $\kappa$, COX-2, 
and iNOS levels (Velmurugan et al., 2010a). GSE was also shown to inhibit intestinal polyp formation and growth in conjunction with increased apoptosis, decreased levels of inflammatory markers, and increased expression of the cyclin-dependent kinase inhibitor Cip1/p21in APC (min/+) mice (Velmurugan et al., 2010b).

Displaying selectivity, resveratrol performs an antioxidant role for normal cells, yet acts as a pro-oxidant for malignant cells; DNA damage and apoptosis were observed to be enhanced in the low $\mathrm{pH}$ environment established by glycolytically active cancer cells (Muqbil et al., 2012). The selective induction of oxidative stress within cancer cells may underlie the proapoptotic actions of GSE through ERK1/2 phosphorylation and arrest of the cell cycle via p21 induction (Kaur et al., 2011). The flavonoid procyanidins found in GSE have been shown to regulate additional cell signaling and mitogenic pathways important for cancer. In prostate cancer cells, GSE greatly limited autocrine feedback of EGF/EGFR/ERK signaling and induced JNK-related apoptosis in the DU145 androgen-independent line (Tyagi et al., 2003). Proanthocyanidins from GSE also induced apoptosis in the Caco-2 colon cancer cell line, partially mediated through attenuation of PI3K signaling (Engelbrecht et al., 2007). Our laboratory has investigated the effects of GSE on cell viability of the colon cancer lines HCT116, HT29, HCT115, and Caco-2, and our results revealed cytotoxic effects in all four lines, which vary widely in their genetic profiles (Sokolosky and Wargovich, unpublished data).

Roots, leaves, and tree barks can also contain powerful substances recognized for their medicinal values in Ayurvedic, Chinese, and traditional South American medicine. GT, the most widely consumed beverage worldwide after water, has received recent popularity due to its broad spectrum ability to fight inflammation and decrease the risks for many types of malignancy. Polyphenols from GT have been shown to possess extremely high antioxidant capacities given their numerous hydroxyl groups, as well as the ability to enhance B- and T-cell mediated immunity (notably within the tumor microenvironment). The most abundant polyphenol from GT, EGCG, has been shown to bind the metastasis-associated $67-\mathrm{kDa}$ laminin receptor at nanomolar concentrations, expression of which can sensitize cancer cells to this compound's anti-proliferative effects (Tachibana et al., 2004). EGCG exhibited selective apoptotic and growth limiting properties in cancer cells through caspase cleavage, inhibition of NF- $\mathrm{kB}$, and modification of cell cycle protein expression (Butt and Sultan, 2009). In addition to inducing cancer cell apoptosis, EGCG also induced death in bone-resorbing osteoclasts in an $\mathrm{Fe}^{2+}$ and $\mathrm{H}_{2} \mathrm{O}_{2}$ dependent manner, with two of the EGCG hydroxyl groups being crucial for this biological activity (Nakagawa et al., 2007). Inhibition of osteoclast function can serve to remodel the hematopoietic stem cell (HSC) niche, thereby inducing differentiation and reducing HSC numbers in vivo (Lymperi et al., 2011). Therefore, compounds such as EGCG may be able to induce differentiation of CSCs, similar to how Vitamin D3 can induce differentiation in mesenchymal stem cells (Piek et al., 2010) as well as many forms of cancer (Gocek and Studzinski, 2009). Furthermore, certain GT catechins, including EGCG, exhibit not only cellular, but species specificity as reflected by their ability to inhibit mammalian DNA polymerases in vitro, but not plant or prokaryotic polymerases (Mizushina et al., 2005).
It has been shown by our laboratory that EGCG can inhibit COX-2 expression during colon carcinogenesis (Peng et al., 2006a), and exert anti-proliferative effects during Ras-induced transformation of intestinal epithelial cells (Peng et al., 2006b). Upstream events at the plasma membrane which lead to aberrant activation of Ras and other kinases can be mediated by lipid rafts that act as signaling hubs. These lipid regions reflect variable compositions between transformed and benign cells as well as apoptotic and viable cells, which may mediate the targeted effects observed with EGCG (Patra et al., 2008). By reorganizing lipid rafts of colon cancer cells, EGCG caused sequestration of EGFRs away from the cell surface via endosomal vesicles; the process of which can be chemopreventive by limiting EGF-induced pathway activation (Adachi et al., 2008). EGCG was also shown to downregulate expression of enzymes involved in gluconeogenesis in murine intestinal cells and Caco-2 colon cancer cells, demonstrating that GT may be able to limit glycolytic activity in premalignant and malignant tissues (Yasui et al., 2011). In a large, randomized clinical trial investigating the effects of GT extract on the recurrence of metachronous colorectal adenoma, the patient group that consumed the extract (dosage equivalent to about 10 cups of GT per day) experienced a $50 \%$ reduction in incidence along with smaller sizes of relapsed tumors; no negative side effects were observed in the extract-treated patients (Shimizu et al., 2008). EGCG was also shown to suppress colony formation ability of MCF-7 breast cancer cells while delaying onset and reducing the size of tumors in a xenograft model. These effects correlated with potent inhibition of HSP70 and HSP90, thus demonstrating that heat shock responses are targets of EGCG antitumor mechanisms (Tran et al., 2010).

Additional findings involving the role of numerous phytonutrients in the chemoprevention of colon cancer are available, as the colon is an attractive model of study given the accumulation and bioavailability of these compounds in this region after ingestion. However, it should be noted that conflicting data exists concerning the combined effects of a phytochemical-rich diet and chemotherapy or radiotherapy. One study found that EGCG significantly lowered the apoptotic abilities of radiotherapy in DU145 prostate cancer cells, suggesting that the potent antioxidant properties of one counteract the free radical generating mechanisms of the other, either of which would be more beneficial alone (Thomas et al., 2011). On the other hand, a study of breast cancer patients undergoing radiotherapy found that concurrent EGCG intake led to lower levels of secreted factors like VEGF and MMP-9 and MMP-2, suggesting anti-angiogenic and anti-metastatic effects. When sera obtained from these patients was added to MDA-MB-231 cultures, anti-proliferative and proapoptotic changes occurred, and EGCG treatment was able to enhance the apoptotic efficacy of $\gamma$-radiation in these cells, which correlated with reduced Akt and NF-кB activity (Zhang et al., 2012a). In another human-based study, mucosal cells from colon cancer patients revealed significant changes in diagnostically relevant DNA methylation as compared to normal colonic mucosa, many of which led to altered expression of glycolytic hormones and enzymes. This suggests that certain dietary compounds will be metabolized differently between the groups of patients, which should be a consideration when selecting therapy, especially metabolically targeted therapy (Silviera et al., 2012). 
Therefore, the dynamic interactions evoked in the presence of various pro- and anti-inflammatory dietary compounds, plant-based phytochemicals, and environmental toxins within a cancer patient could have a profound and clinically relevant influence on their response to conventional and/or alternative therapy.

\section{REBALANCING THE TIPPED EPIGENETIC SCALE}

In light of the complex array of factors underlying chronic disease in modernized societies, it is likely that epigenetic regulation of gene expression via exogenously obtained compounds plays a critical role in the emergence of homeostatic imbalance, as shown in Figure 2. In addition to focusing on the cellular and organ level, the entire physiological system must be considered, including circulating metabolites of environmental toxins and plant compounds, to yield a more comprehensive understanding of a living organism. The Human Metabolome Database is an updated, annotated library of metabolites found to exist within the human body, and can serve as a resource for scientists and clinicians (Wishart et al., 2009). By integrating an individual's genomic, proteomic, and metabolomic information, medical science could be more effectively equipped to approach disease prevention and treatment. The identification of new biomarkers will be vital to further defining colorectal cancer risk, designing individualized therapies, and planning practical preventive interventions relevant to the population of focus (Risio, 2011). Panels to assess circulating inflammatory mediators and xenobiotic compounds in the blood could represent a new class of measurable markers in personalized health care.

Tumor progression is a dynamic process in which the commitment to malignancy is not firm, but fluctuates between progression, stabilization, and regression dependent upon adaptation, or the lack thereof, to selective stimuli. Precancerous cells exhibit a range of evolutive speeds, representative of a complex array of genetic and non-genetic factors, and these speeds can be influenced by environmental switches within the human epigenome (Risio, 2011). According to the maximum genetic diversity hypothesis, evolution from simpler to more complex organisms involves an elevation in epigenetic complexity that occurs at the expense of genetic (mutation-driven) diversity among individuals. This inverse relationship between two forms of gene expression regulation can expand upon classical Darwinian definitions of evolution to further explain how diverse phenotypes arise within a closely related population in a relatively short span of time (Huang, 2008). It is in this way that one identical twin can develop a metastatic tumor while the other twin, in spite of sharing the same germ line DNA, can remain cancer-free by virtue of their unique epigenetic profiles.

It is possible that sporadic and familial cancers without clear causation are the result of both inherited genes for susceptibility and inherited epigenetic footprints that run in a particular lineage. Epigenetic changes passed on to daughter cells are just as relevant as mutations, especially in organs that undergo high rates of renewal while simultaneously being exposed to high toxin levels such as the lungs, breasts, and GI tract. Alarmingly, common toxins have now been shown to exert inherited effects in animal models in which an exposure to an EDC in a pregnant female induces epigenetic modifications that are passed on to each subsequent generation of males, as evidenced by altered DNA methylation patterns in the germ line. This transgenerational (TG) effect occurred in the absence of direct exposure of the offspring to the causative agent (Anway et al., 2005). Further investigation into the TG actions of mixed toxins in F0 gestating rats revealed effects in the F1-F3 generations such as early puberty and spermatogenic apoptosis stemming from the original F0 exposure. Epigenetic markers within differential DNA methylation regions of sperm cells from unexposed offspring conveyed correlations with specific ancestral exposures, with 499 genes identified to be associated with TG effects (Manikkam et al., 2012). Additional elucidation of the in vivo epigenetic mechanisms of common toxins in normal, precancerous, and malignant cells is strongly encouraged. Based on present data, it is important for the scientific and medical communities to increase the general public's awareness of toxins in their every lives, as well as promote practical and affordable methods of prevention. Given that EDC exposure is virtually unavoidable in some cases, once bioaccumulation has occurred, therapies and interventions that accelerate detoxification and elimination of persistent toxins from the body would be clinically relevant and could ameliorate current management approaches for chronic illness (Genuis, 2011).

By practicing prudent avoidance of toxins and obtaining consistent levels of dietary phytochemicals, we can restore and maintain physiological balance by limiting negative epigenetic changes and promoting protective ones. For example, cooking with onions and garlic can neutralize many of the carcinogens created by highheat preparation of food, thereby limiting a preventable exposure. Thus, to maintain epigenetic balance it is imperative to properly fortify the body by consuming a diverse diet rich in whole plant foods, herbs, and spices. GSE was shown to exert potent epigenetic regulation in androgen-responsive $\mathrm{LNCaP}$ cells by inhibiting histone acetyltransferase (HAT) activity up to $80 \%$, in addition to significantly decreasing androgen receptor mediated transcription (Park et al., 2011). Resveratrol has been shown to directly counteract the negative effects of toxin exposure by acting as an antagonist for the AhR, of which dioxin and benzo[a]pyrene are ligands. Therefore, prophylactic resveratrol could offer a non-toxic and potent way to limit expression of dioxin-inducible genes like cytochrome p4501A1 and IL-1 $\beta$, upon aryl hydrocarbon exposure (Casper et al., 1999). The prevention of BPA-induced toxicity in Sertoli cells was also achievable through pre-treatment with ginsenoside compounds from Ginseng, suggesting that the effects of environmental exposures can be limited if phytochemicals are present (Wang et al., 2012a).

Remarkably, EGCG is able to hydrogen bond within the active site of DNA methyltransferase (DNMT), thereby inhibiting its cancer promoting functions and turning on previously silenced genes in prostate cancer cells (Fang et al., 2003). EGCG has also been shown to induce histone deacetylation and promoter hypomethylation to achieve repression of hTERT, the catalytic subunit of telomerase, which is overexpressed in $90 \%$ of cancers. This effect induced apoptosis in MCF-7 breast cancer cells, and EGCG also induced apoptosis in HL60 leukemia cells, although via a different mechanism (Berletch et al., 2008). hTERT promoter demethylation by EGCG was also observed in ER+ MCF-7 and ERMDA-MB-231 breast cancer cells through inhibition of DNMT 


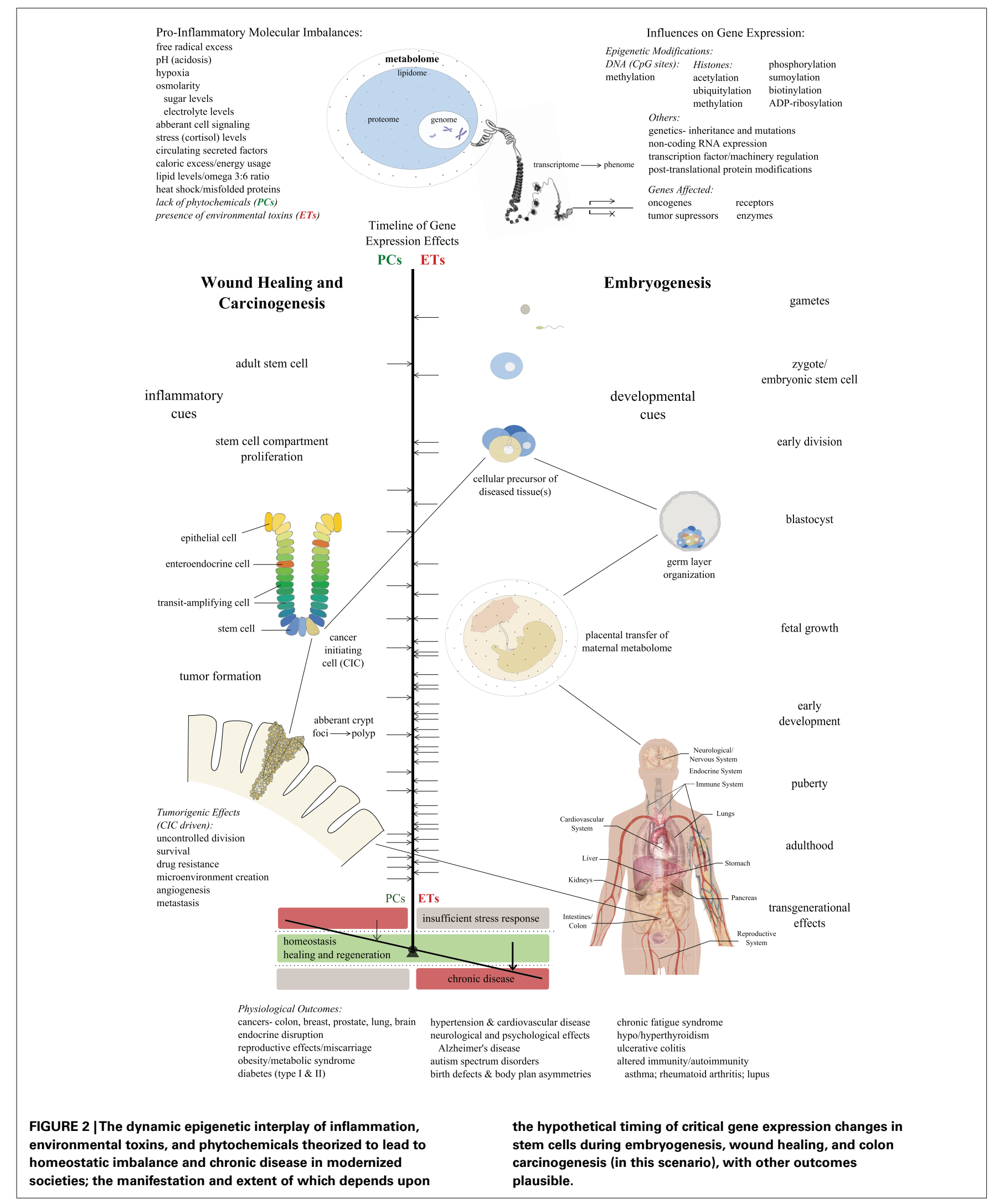


and HAT activity (Meeran et al., 2011). Another study found that EGCG epigenetically repressed promoter methylation of the tumor suppressors p16 and p15, thereby restoring their expression and inhibiting proliferation of colon cancer cells (Berner et al., 2010). EGCG can also alter levels of the universal methyl donor, $S$-adenosylmethionine, and the methyltransferase inhibitor, $S$ adenosylhomocysteine, thereby indirectly influencing epigenetic regulation (Park et al., 2012). Therefore, phytochemicals offer chemopreventive mechanisms important for reestablishing tumor suppressor activity previously silenced during oncogenesis.

It should be noted that exogenous hormone exposure can occur via ingestion of certain plants, but these non-steroidal natural compounds appear to behave differently than synthetic EDCs. Genistein and resveratrol, which are classified as phytoestrogens, were shown to exert epigenetic regulation of the estrogen receptor $\alpha 1$ (ESR1) gene in colon cancer cells, demonstrating that a wide array of mechanisms can be modulated by bioactive food compounds (Berner et al., 2010). It was also shown that genistein can inhibit proliferation by downregulating WNT5a promoter methylation in colon cancer cells (Wang and Chen, 2010). It is interesting to note that genistein and other isoflavones mediate their effects in humans through selective binding to ER $\beta$ as opposed to ER $\alpha$ (Barone et al., 2011). Whereas the growth-promoting ER $\alpha$ isoform tends to be upregulated in hormonally responsive cancers, signaling through the ER $\beta$ isoform, which may serve a tumor suppressor role, is often downregulated via a variety of mechanisms.

It was found that genistein promoted anti-proliferative and proapoptotic effects through ER $\beta$ in the large and small intestine (Schleipen et al., 2011), circumvention of such may be why cancers specifically upregulate expression of the growth-promoting ER $\alpha$ isoform. In respect to normal adipocytes, genistein was shown to inhibit leptin secretion by limiting glucose metabolism (Szkudelski et al., 2005). Genistein, resveratrol, and quercetin were shown to exhibit enhanced inhibition of adipogenesis and promotion of apoptosis when used in combination to treat human and murine adipocytes, effects of which correlated with a decrease in glycerol 3phosphate dehydrogenase activity (Park et al., 2008). These results suggest that dietary intake of various phytoestrogens may carry implications for appetite control, sugar metabolism, and aberrant glycolytic activity within cancer cells, with effects being opposite of those observed for EDCs. However, the full gamut of phytoestrogen activity remains to be characterized as studies in breast cancers have revealed different effects depending upon ER, as well as HER2 expression. The relative expression levels of ER $\alpha$ and ER $\beta$ within a normal or cancerous cell can greatly influence proliferation, endocrine signaling, and response to various ER ligands (Chang et al., 2006a), both plant-derived and manmade.

As for synthetic EDCs, BPA, and others bind to ER $\alpha$ and stimulate signaling, but upon binding to $\operatorname{ER} \beta$, fail to trigger the anti-proliferative activities of this receptor subtype (Bolli et al., 2010). BPA also may bind to the estrogen-related receptor gamma $(\mathrm{ERR} \gamma)$ as indicated in neuronal studies (Tanabe et al., 2012), thereby suggesting numerous cellular targets of EDCs. It should be noted that in certain situations, ER $\alpha$ signaling may be capable of preserving the epithelial phenotype and limiting EMT, the effect of which has been observed in breast cancer cells (Guttilla et al., 2012), although the loss of hormone-responsiveness would overcome this possible anti-metastatic effect of excessive ER $\alpha$ stimulation via EDCs. The tissue-selective agonist and antagonistic effects of xenoestrogens occur based in the relative expression of ER isoforms, much in the way that hormonal contraceptives and the selective ER modulator, Tamoxifen, can exhibit tissue-specific effects in the ovaries and breasts. In general, xenohormones are a risk factor in colon cancer through imbalanced nuances of ER $\alpha$ and ER $\beta$ expression; a tip in either direction could have cancer promoting consequences. Therefore, phytoestrogens may be the natural answer for balancing the effects of artificial xenoestrogens, as these two types of compounds appear to serve as agonists and/or antagonists for similar cellular targets, as detailed in Table 1 and Figure 3. In fact, the estrogenic potency of phytoestrogens may be greater than environmental estrogens, as genistein was shown to stimulate respective ER transcriptional activity at much lower nanomolar concentrations than those required for BPA (Kuiper et al., 1998). Maternal dietary supplementation with folic acid (methyl donor) or genistein was able to limit the CpG hypomethylation otherwise induced by BPA exposure, demonstrating that epigenetic balance can be restored through appropriate nutrient intake (Dolinoy et al., 2007). The full epigenetic regulatory spectrum of natural compounds is currently being defined and additional mechanisms involving the gene expression modifying enzymes, DNMTs, HATs, and histone deacetylases (HDACs) are likely to be elucidated.

Unparalleled selectivity is reflected in natural products, as well as extremely low or absent toxicity when compared to other chemopreventive agents such as the non-steroidal antiinflammatory drugs, which can induce bleeding and ulceration. Whereas inhibitors of COX-1 and COX-2 have been shown to counteract chronic inflammation and lower cancer risk, they carry substantial cardiovascular concerns and liver toxicity with prolonged use. The apparent influence of fat intake on inflammation can be exerted beneficially by establishing an ideal FA ratio through consumption of omega-3 rich foods and restriction of omega- 6 sources. In a model of experimentally induced colitis, ALA, an omega-3 FA, was able to reduce oxidative stress and counteract inflammation via suppression of NF- $\kappa \mathrm{B}$ and COX-2 activity (Hassan et al., 2010).

In another colitis study, Krill oil, rich in omega-3 FAs, acted in an anti-inflammatory manner to decrease oxidative stress and cytokine secretion in dextran sulfate sodium-treated mice (Grimstad et al., 2012). In addition to ideal FA ratios, an approach to addressing inflammation could be based on intake of flavorful, sometimes pungent, and often bitter plant compounds in their native configurations from whole-food sources like turmeric, ginger, cinnamon, broccoli, chili peppers, coffee, tea, dark chocolate, and fruit seeds. A phytochemically diverse diet creates beneficial synergistic effects, and certain compounds can facilitate proper transport and absorption of other nutrients, as in the case of piperine from black pepper and vitamin C intake with plant-based meals. In addition to nutrient intake, consumption of probiotics can establish and maintain beneficial gut microflora that stimulate immunity and assist in the elimination of toxins. For example, it was shown that when fed a diet containing a Bifidobacterium or Lactobacillus strains, BPA-exposed rats had a reduced BPA blood concentration over time and 2.4-fold increase in BPA fecal 


\section{7ß-estradiol}<smiles>CC12CCC3c4ccc(O)cc4CCC3C1CCC2O</smiles>

Environmental Estrogens:

Phytoestrogens:

Bisphenol-A<smiles>CC(C)(c1ccc(O)cc1)c1ccc(O)cc1</smiles>

\section{Resveratrol}<smiles>Oc1ccc(C=Cc2cc(O)cc(O)c2)cc1</smiles>

Paraben (methyl-, ethyl-, propyl-, butyl-)

Genistein<smiles>O=C(O)c1ccc(O)cc1</smiles><smiles>O=c1c(-c2ccc(O)cc2)coc2cc(O)cc(O)c12</smiles>

Tamoxifen- clinical ER modulator<smiles>CCC(=C(c1ccccc1)c1ccccc1)c1ccc(OCCN(C)C)cc1</smiles>

FIGURE 3 | Structures of common xenoestrogens capable of influencing estrogenic signaling through agonistic and/or antagonistic mechanisms.

excretion (Oishi et al., 2008). Therefore, dietary alterations can be powerful tools for counteracting modern environmental exposures by restoring inflammation to a proper range in which chronic states are suppressed but vital acute responses still efficiently occur.

We can acknowledge the finely tuned adaptations of mammalian cells for plant compounds and draw on the order of sophistication and simplicity only attained in nature. In the lab, we can explore the development of nutraceuticals with slight chemical modifications that increase their absorption, bioavailability, and stability in vivo while maintaining natural potency. A novel prodrug form of EGCG containing peracetate-protected hydroxyl groups was shown have increased stability and enhanced uptake within breast cancer cells, where it was able to selectively repress telomerase expression in an epigenetic manner, as compared to non-transformed control cells (Meeran et al., 2011). In another study, acylated catechin derivatives had enhanced anti-cancer and anti-angiogenic properties compared to FA-conjugated epicatechins in HCT116 cells, with stearic acid-modified catechin demonstrating the highest level of efficacy (Mizushina et al., 2011). By elucidating the structure-activity relationships and computationally visualizing the molecular interactions of phytochemicals, chemists can seek to improve their pharmacokinetic/dynamic profiles. However, a chemically modified and synthetically derived compound may not exhibit the same subtle nuances that it would if produced in its natural state, so plant-based culture systems for experimental and large-scale phytochemical production may be preferable.

It is important to recognize that drug-drug interactions between bioactive food compounds and pharmaceutical agents are a concern, as cytochrome-mediated drug metabolism and/or bioavailability may be altered by phytochemicals in some scenarios. In the presence of EGCG, studies have found increased bioavailability of Tamoxifen (Shin and Choi, 2009), but decreased bioavailability for the RTK inhibitor Sunitinib (Ge et al., 2011). Decreased efficacy of the boronic acid-based proteosome inhibitor Bortezomib has also been linked to EGCG, with direct binding of the two compounds shown to mediate the interaction (Golden et al., 2009). Therefore, consumption of GT would be an important contraindication during certain therapeutic windows. High EGCG intake during pregnancy is also contraindicated as recent 
findings link this topoisomerase-inhibiting flavonoid to MLL gene cleavages and translocations, implicated in infant leukemia (Strick et al., 2000).

Another limitation of oral phytochemical usage can be absolute bioavailability, mostly due to oxidation, rapid absorption, and/or microbial enzymatic cleavage in the GI tract. However, consistent dietary intake is likely sufficient for establishing blood and tissue concentrations within the low range required for chemopreventive effects. EGCG accumulation within prostatectomy tissue was achievable with daily GT consumption by prostate cancer patients, although it should be noted that $50 \%$ of the EGCG present had been methylated to $4^{\prime \prime}$-MeEGCG, which appears to reduce its antitumor effects (Wang et al., 2010). It is interesting to note that when combined with quercetin, which inhibits catechol$O$-methyltransferase and drug efflux pumps, EGCG methylation was decreased by threefold and uptake increased by fourfold in lung cancer cells (Wang et al., 2012b). Once again, these findings support the idea that chemopreventive properties are maximized when a variety of plant-based foods are consumed. As an alternative to maintaining systemic bioavailability from oral dosage, therapeutic levels may be achieved locally with bioengineered delivery systems such as implantable scaffolds and hydrogels constructed from natural polymers. Non-oral routes of phytochemical dosage such as inhalation, intravenous, or epidermal application would also be worth investigating. Modern drug discovery, design, and delivery have relied heavily on cues from nature, and although not a panacea, natural products have revealed numerous medicinal mechanisms that could positively impact human health, with many remaining to be investigated. Even without physiological administration, plants can prevent disease by eliminating airborne toxins such as benzene and vinyl chloride, the monomer of PVC, by virtue of photosynthetic and metabolic processes (Doty et al., 2007).

By virtue of large or small-scale production leading to broad availability at grocery chains and markets, plant-based nutrition is accessible, relatively affordable, and easily promoted to society as an important preventive measure against chronic disease. Although, translating this knowledge to common practice is growing increasingly difficult in westernized cultures whose populations opt for nutrient and phytochemical-depleted fast

\section{REFERENCES}

Abdallah, D. M., and Ismael, N. R. (2011). Resveratrol abrogates adhesion molecules and protects against TNBS-induced ulcerative colitis in rats. Can. J. Physiol. Pharmacol. 89, 811-818.

Adachi, S., Nagao, T., To, S., Joe, A. K., Shimizu, M., MatsushimaNishiwaki, R., Kozawa, O., Moriwaki, H., Maxfield, F. R., and Weinstein, I. B. (2008). (-)-Epigallocatechin gallate causes internalization of the epidermal growth factor receptor in human colon cancer cells. Carcinogenesis 29, 1986-1993.

American Cancer Society. (2012). Diet and Physical Activity: What's the Cancer Connection? Available

foods. There is promise however. Researchers can perform discovery science to expose modern roots of disease and further illuminate our knowledge of prevention through the generation of additional hypotheses. We know little about the mechanisms of cellular uptake, transport, and metabolism of many of the compounds mentioned. In an effort to mimic human prevention and disease scenarios, experimental animal models should be employed that reflect realistic dietary conditions (high in fat and low in nutrients and fiber), such as the new Western-style diet (NWD1), which is known to induce inflammatory responses and increase colon cancer occurrence in rodents (Bastie et al., 2012). It should be noted that any exogenous compound, including a natural compound at a high enough concentration, can act as a stressor in cell-based models that ultimately do not reflect physiological conditions. This may explain cases of conflicting data obtained between in vitro and in vivo phytochemical studies, and experiments must be comprehensively designed to address this caveat.

In the clinic, practitioners can incorporate holistic-based medicine within their repertoire to treat a patient's tumor as a symptom while working with them to adjust the underlying physiological imbalances that set the stage for cancers to thrive. Although phytochemical-based approaches cannot reverse extensive preexisting damage or address aggressive, late-stage disease, they can become a mainstay of prevention for healthy patients and an important intervention for patients with manageable conditions. Defining new frontiers in oncology involves reevaluating old paradigms in the context of modern needs, thereby revamping the historically practical wisdom that established the foundation of medicine. The nineteenth century French physiologist Claude Bernard defined the concept of milieu intérieur, or homeostasis, when he proposed to his colleagues that, "the terrain is everything, the germ is nothing." According to legend, he proceeded to drink a glass of cholera-tainted water to prove his point; if only we could be so bold in our endeavors to dethrone, as Siddhartha Mukherjee phrased it, the emperor of all maladies.

\section{ACKNOWLEDGMENTS}

We would like to thank Nathaniel Sexton for sharing recent publications and thought-provoking conversations.

Environ. Mol. Mutagen. [Epub ahead of print].

Anway, M. D., Cupp, A. S., Uzumcu, M., and Skinner, M. K. (2005). Epigenetic transgenerational actions of endocrine disruptors and male fertility. Science 308, 1466-1469.

Barone, M., Lofano, K., De Tullio, N., Licino, R., Albano, F., and Di Leo, A. (2011). Dietary, endocrine, and metabolic factors in the development of colorectal cancer. J. Gastrointest. Cancer 43, 13-19.

Barr, L., Metaxas, G., Harbach, C. A., Savoy, L. A., and Darbre, P. D. (2012). Measurement of paraben concentrations in human breast tissue at serial locations across the breast from axilla to sternum. J. Appl. Toxicol. 32, 219-232.

Bastie, C. C., Gaffney-Stomberg, E., Lee, T. W., Dhima, E., Pessin, J. E., and Augenlicht, L. H. (2012). Dietary cholecalciferol and calcium levels in a Western-style defined rodent diet alter energy metabolism and inflammatory responses in mice. J. Nutr. 142, 859-865.

Berletch, J. B., Liu, C., Love, W. K., Andrews, L. G., Katiyar, S. K., and Tollefsbol, T. O. (2008). Epigenetic and genetic mechanisms contribute to telomerase inhibition by EGCG. J. Cell. Biochem. 103, 509-519.

Berner, C., Aumuller, E., Gnauck, A., Nestelberger, M., Just, A., and Haslberger, A. G. (2010). Epigenetic 
control of estrogen receptor expression and tumor suppressor genes is modulated by bioactive food compounds. Ann. Nutr. Metab. 57, 183-189.

Biro, F. M., Galvez, M. P., Greenspan, L. C., Succop, P. A., Vangeepuram, N., Pinney, S. M., Teitelbaum, S., Windham, G. C., Kushi, L. H., and Wolff, M. S. (2010). Pubertal assessment method and baseline characteristics in a mixed longitudinal study of girls. Pediatrics 126, e583-e590.

Bolli, A., Bulzomi, P., Galluzzo, P., Acconcia, F., and Marino, M. (2010). Bisphenol A impairs estradiolinduced protective effects against DLD-1 colon cancer cell growth. IUBMB Life 62, 684-687.

Bosmann, H. B., and Hall, T. C. (1974). Enzyme activity in invasive tumors of human breast and colon. Proc. Natl. Acad. Sci. U.S.A. 71, 1833-1837.

Braniste, V., Jouault, A., Gaultier, E., Polizzi, A., Buisson-Brenac, C., Leveque, M., Martin, P. G., Theodorou, V., Fioramonti, J., and Houdeau, E. (2010). Impact of oral bisphenol A at reference doses on intestinal barrier function and sex differences after perinatal exposure in rats. Proc. Natl. Acad. Sci. U.S.A. 107, 448-453.

Butt, M. S., and Sultan, M. T. (2009). Green tea: nature's defense against malignancies. Crit. Rev. Food Sci. Nutr. 49, 463-473.

Casper, R. F., Quesne, M., Rogers, I. M., Shirota, T., Jolivet, A., Milgrom, E., and Savouret, J. F. (1999). Resveratrol has antagonist activity on the aryl hydrocarbon receptor: implications for prevention of dioxin toxicity. Mol. Pharmacol. 56, 784-790.

Center, M. M., Jemal, A., and Ward, E. (2009). International trends in colorectal cancer incidence rates. Cancer Epidemiol. Biomarkers Prev. 18, 1688-1694.

Chang, E. C., Frasor, J., Komm, B., and Katzenellenbogen, B. S. (2006a). Impact of estrogen receptor beta on gene networks regulated by estrogen receptor alpha in breast cancer cells. Endocrinology 147, 4831-4842.

Chang, H. K., Shin, M. S., Yang, H. Y., Lee, J. W., Kim, Y. S., Lee, M. H., Kim, J., Kim, K. H., and Kim, C. J. (2006b). Amygdalin induces apoptosis through regulation of Bax and $\mathrm{Bcl}-2$ expressions in human DU145 and LNCaP prostate cancer cells. Biol. Pharm. Bull. 29, 1597-1602.

Chang, H. K., Yang, H. Y., Lee, T. H., Shin, M. C., Lee, M. H., Shin, M. S., Kim, C. J., Kim, O. J., Hong, S. P., and Cho, S. (2005). Armeniacae semen extract suppresses lipopolysaccharide-induced expressions of cyclooxygenase [correction of cycloosygenase]-2 and inducible nitric oxide synthase in mouse BV2 microglial cells. Biol. Pharm. Bull.28, 449-454.

Cheah, K. Y., Howarth, G. S., Yazbeck, R., Wright, T. H., Whitford, E. J., Payne, C., Butler, R. N., and Bastian, S. E. (2009). Grape seed extract protects IEC-6 cells from chemotherapy-induced cytotoxicity and improves parameters of small intestinal mucositis in rats with experimentally-induced mucositis. Cancer Biol. Ther. 8, 382-390.

Corbel, V., Stankiewicz, M., Pennetier, C., Fournier, D., Stojan, J., Girard, E., Dimitrov, M., Molgo, J., Hougard, J. M., and Lapied, B. (2009). Evidence for inhibition of cholinesterases in insect and mammalian nervous systems by the insect repellent deet. BMC Biol. 7, 47. doi:10.1186/1741-7007-7-47

Corsini, E., Sangiovanni, E., Avogadro, A., Galbiati, V., Viviani, B., Marinovich, M., Galli, C. L., Dell'Agli, M., and Germolec, D. R. (2012). In vitro characterization of the immunotoxic potential of several perfluorinated compounds (PFCs). Toxicol. Appl. Pharmacol. 258, 248-255.

Coussens, L. M., and Werb, Z. (2002). Inflammation and cancer. Nature 420, 860-867.

Cozzolino, R., Palladino, P., Rossi, F., Cali, G., Benedetti, E., and Laccetti, P. (2005). Antineoplastic cyclic astin analogues kill tumour cells via caspase-mediated induction of apoptosis. Carcinogenesis 26, 733-739.

Cragin, L. A., Kesner, J. S., Bachand, A. M., Barr, D. B., Meadows, J. W., Krieg, E. F., and Reif, J. S. (2011). Menstrual cycle characteristics and reproductive hormone levels in women exposed to atrazine in drinking water. Environ. Res. 111, 1293-1301.

Dann, A. B., and Hontela, A. (2011). Triclosan: environmental exposure, toxicity and mechanisms of action. J. Appl. Toxicol. 31, 285-311.

David, A. R., and Zimmerman, M. R. (2010). Cancer: an old disease, a new disease or something in between? Nat. Rev. Cancer 10, 728-733.

Dinicola, S., Cucina, A., Pasqualato, A., Proietti, S., D'Anselmi, F., Pasqua, G., Santamaria, A. R., Coluccia, P., Laganà, A., Antonacci, D., Giuliani, A., and Bizzarri, M. (2010). Apoptosis-inducing factor and caspase-dependent apoptotic pathways triggered by different grape seed extracts on human colon cancer cell line Caco-2. Br. J. Nutr. 104, 824-832.

Doherty, L. F., Bromer, J. G, Zhou, Y., Aldad, T. S., and Taylor, H. S. (2010). In utero exposure to diethylstilbestrol (DES) or bisphenol-A (BPA) increases EZH2 expression in the mammary gland: an epigenetic mechanism linking endocrine disruptors to breast cancer. Horm. Cancer 1, 146-155.

Dolinoy, D. C., Huang, D., and Jirtle, R. L. (2007). Maternal nutrient supplementation counteracts bisphenol A-induced DNA hypomethylation in early development. Proc. Natl. Acad. Sci. U.S.A. 104, 13056-13061.

Doshi, T., Mehta, S. S., Dighe, V., Balasinor, N., and Vanage, G. (2011). Hypermethylation of estrogen receptor promoter region in adult testis of rats exposed neonatally to bisphenol A. Toxicology 289 , 74-82.

Doty, S. L., James, C. A., Moore, A. L., Vajzovic, A., Singleton, G. L., Ma, C., Khan, Z., Park, J. Y., Meilan, R., Strauss, S. H., Wilkerson, J., Farin, F., and Strand, S. E. (2007). Enhanced phytoremediation of volatile environmental pollutants with transgenic trees. Proc. Natl. Acad. Sci. U.S.A. 104, 16816-16821.

Dua, V. K., Pandey, A. C., Raghavendra, K., Gupta, A., Sharma, T., and Dash, A. P. (2009). Larvicidal activity of neem oil (Azadirachta indica) formulation against mosquitoes. Malar. J. 8, 124.

Dunn, B. (2012). Cancer: solving an age-old problem. Nature 483, S2-S6.

Engelbrecht, A. M., Mattheyse, M., Ellis, B., Loos, B., Thomas, M., Smith, R. Peters, S., Smith, C., and Myburgh, K. (2007). Proanthocyanidin from grape seeds inactivates the PI3kinase/PKB pathway and induces apoptosis in a colon cancer cell line. Cancer Lett. 258, 144-153.

Environmental Working Group. (2011). Shopper's Guide to Pesticides in Produce. Available at: http://www.ewg.org/foodnews/ methodology [accessed January 7, 2012].

Environmental Working Group. (2009). Pollution in People: Cord Blood Contaminants in Minority Newborns. Available at: http://www. ewg.org/files/2009-Minority-CordBlood-Report.pdf [accessed January 7, 2012].

Fang, M. Z., Wang, Y., Ai, N., Hou, Z., Sun, Y., Lu, H., Welsh, W., and Yang, C. S. (2003). Tea polyphenol (-)-epigallocatechin-3-gallate inhibits DNA methyltransferase and reactivates methylation-silenced genes in cancer cell lines. Cancer Res. 63, 7563-7570.

Farah, M. A., Ateeq, B., and Ahmad, W. (2006). Antimutagenic effect of neem leaves extract in freshwater fish, Channa punctatus evaluated by cytogenetic tests. Sci. Total Environ. 364, 200-214.

Fazekas de St Groth, B. (2012). Regulatory T-cell abnormalities and the global epidemic of immunoinflammatory disease. Immunol. Cell Biol. 90, 256-259.

Fox, E. M., Davis, R. J., and Shupnik, M. A. (2008). ERbeta in breast cancer onlooker, passive player, or active protector? Steroids 73, 1039-1051.

Fukuda, T., Ito, H., Mukainaka, T., Tokuda, H., Nishino, H., and Yoshida, T. (2003). Anti-tumor promoting effect of glycosides from Prunus persica seeds. Biol. Pharm. Bull. 26, 271-273.

Ge, J., Tan, B. X., Chen, Y., Yang, L., Peng, X. C., Li, H. Z., Lin, H. J., Zhao, Y., Wei, M., Cheng, K., Li, L. H., Dong, H., Gao, F., He, J. P., Wu, Y., Qiu, M., Zhao, Y. L., Su, J. M., Hou, J. M., and Liu, J. Y. (2011). Interaction of green tea polyphenol epigallocatechin-3-gallate with sunitinib: potential risk of diminished sunitinib bioavailability. J. Mol. Med. (Berl.) 89, 595-602.

Genuis, S. J. (2011). Elimination of persistent toxicants from the human body. Hum. Exp. Toxicol. 30, 3-18.

GLOBOCAN Colorectal Cancer Data. (2008). Available at: http://globocan.iarc.fr/factsheets/ cancers/colorectal.asp [accessed January 15, 2012].

Gocek, E., and Studzinski, G. P. (2009). Vitamin D and differentiation in cancer. Crit. Rev. Clin. Lab. Sci. 46, 190-209.

Golden, E. B., Lam, P. Y., Kardosh, A., Gaffney, K. J., Cadenas, E., Louie, S. G., Petasis, N. A., Chen, T. C., and Schonthal, A. H. (2009). Green tea polyphenols block the anticancer effects of bortezomib and other boronic acid-based proteasome inhibitors. Blood 113, 5927-5937.

Grandjean, P., Andersen, E. W., BudtzJorgensen, E., Nielsen, F., Molbak, K., Weihe, P., and Heilmann, C. (2012). Serum vaccine antibody concentrations in children exposed to perfluorinated compounds. JAMA 307 , 391-397.

Grandjean, P., and Heindel, J. J. (2008). In utero and early-life conditions and adult health and disease. N. Engl. J. Med. 359, 1523.

Greenman, S. B., Rutten, M. J., Fowler, W. M., Scheffler, L., Shortridge, L. 
A., Brown, B., Sheppard, B. C., Deveney, K. E., Deveney, C. W., and Trunkey, D. D. (1997). Herbicide/pesticide effects on intestinal epithelial growth. Environ. Res. 75, 85-93.

Griffin, G. E. (1974). World Without Cancer. Boca Raton, FL: American Media.

Grimstad, T., Bjorndal, B., Cacabelos, D., Aasprong, O. G., Janssen, E. A., Omdal, R., Svardal, A., Hausken, T., Bohov, P., Portero-Otin, M., Pamplona, R., and Berge, R. K. (2012). Dietary supplementation of krill oil attenuates inflammation and oxidative stress in experimental ulcerative colitis in rats. Scand. J. Gastroenterol. 47, 49-58.

Grun, F. (2010). Obesogens. Curr. Opin. Endocrinol. Diabetes Obes. 17, 453-459.

Guttilla, I. K., Adams, B. D., and White, B. A. (2012). ERalpha, microRNAs, and the epithelialmesenchymal transition in breast cancer. Trends Endocrinol. Metab. 23, 73-82.

Hassan, A., Ibrahim, A., Mbodji, K., Coeffier, M., Ziegler, F., Bounoure, F., Chardigny, J. M., Skiba, M., Savoye, G., Déchelotte, P., and MarionLetellier, R. (2010). An alphalinolenic acid-rich formula reduces oxidative stress and inflammation by regulating NF-карраB in rats with TNBS-induced colitis. J. Nutr. 140, 1714-1721.

Hayes, T. B., Anderson, L. L., Beasley, V. R., de Solla, S. R., Iguchi, T., Ingraham, H., Kestemont, P., Kniewald, J., Kniewald, Z., Langlois, V. S., Luque, E. H., McCoy, K. A., Muñoz-de-Toro, M., Oka, T., Oliveira, C. A., Orton, F., Ruby, S., Suzawa, M., TaveraMendoza, L. E., Trudeau, V. L., Victor-Costa, A. B., Willingham, E. (2011). Demasculinization and feminization of male gonads by atrazine: consistent effects across vertebrate classes. J. Steroid Biochem. Mol. Biol. 127, 64-73.

Hayes, T. B., Khoury, V., Narayan, A., Nazir, M., Park, A., Brown, T., Adame, L., Chan, E., Buchholz, D., Stueve, T., and Gallipeau, S. (2010). Atrazine induces complete feminization and chemical castration in male African clawed frogs (Xenopus laevis). Proc. Natl. Acad. Sci. U.S.A. 107, 4612-4617.

Hochberg, Z., Feil, R., Constancia, M., Fraga, M., Junien, C., Carel, J. C., Boileau, P., Le Bouc, Y., Deal, C. L., Lillycrop, K., Scharfmann, R., Sheppard, A., Skinner, M., Szyf, M., Waterland, R. A., Waxman, D. J., Whitelaw, E., Ong, K., and Albertsson-Wikland, K. (2011). Child health, developmental plasticity, and epigenetic programming. Endocr. Rev. 32, 159-224.

Hsu, P. Y., Deatherage, D. E., Rodriguez, B. A., Liyanarachchi, S., Weng, Y. I., Zuo, T., Liu, J., Cheng, A. S., and Huang, T. H. (2009). Xenoestrogeninduced epigenetic repression of microRNA-9-3 in breast epithelial cells. Cancer Res. 69, 5936-5945.

Huang, S. (2008). "Histone methylation and the initiation of cancer," in Cancer Epigenetics, ed. T. Tollefsbol (Boca Raton, FL: CRC Press).

Johansson, N., Fredriksson, A., and Eriksson, P. (2008). Neonatal exposure to perfluorooctane sulfonate (PFOS) and perfluorooctanoic acid (PFOA) causes neurobehavioral defects in adult mice. Neurotoxicology 29, 160-169.

Kaur, M., Tyagi, A., Singh, R. P., Sclafani, R. A., Agarwal, R., and Agarwal, C. (2011). Grape seed extract upregulates p21 (Cip1) through redoxmediated activation of ERK1/2 and posttranscriptional regulation leading to cell cycle arrest in colon carcinoma HT29 cells. Mol. Carcinog. 50, 553-562.

Kleszczynski, K., and Skladanowski, A. C. (2009). Mechanism of cytotoxic action of perfluorinated acids. I. alteration in plasma membrane potential and intracellular $\mathrm{pH}$ level. Toxicol. Appl. Pharmacol. 234, 300-305.

Kuiper, G. G., Lemmen, J. G., Carlsson, B., Corton, J. C., Safe, S. H., van der Saag, P. T., van der Burg, B., and Gustafsson, J. A. (1998). Interaction of estrogenic chemicals and phytoestrogens with estrogen receptor beta. Endocrinology 139, 4252-4263.

Lamartiniere, C. A., Jenkins, S., Betancourt, A. M., Wang, J., and Russo, J. (2011). Exposure to the endocrine disruptor bisphenol A alters susceptibility for mammary cancer. Horm. Mol. Biol. Clin. Investig. 5, 45-52.

Lang, I. A., Galloway, T. S., Scarlett, A., Henley, W. E., Depledge, M., Wallace, R. B., and Melzer, D. (2008). Association of urinary bisphenol A concentration with medical disorders and laboratory abnormalities in adults. JAMA 300, 1303-1310.

Liekens, S., Schols, D., and Hatse, S. (2010). CXCL12-CXCR4 axis in angiogenesis, metastasis and stem cell mobilization. Curr. Pharm. Des. 16, 3903-3920.

Lymperi, S., Ersek, A., Ferraro, F., Dazzi, F., and Horwood, N. J. (2011). Inhibition of osteoclast function reduces hematopoietic stem cell numbers in vivo. Blood 117, 1540-1549.
Lysaght, J., van der Stok, E. P., Allott, E. H., Casey, R., Donohoe, C. L., Howard, J. M., McGarrigle, S. A., Ravi, N., Reynolds, J. V. and Pidgeon, G. P. (2011). Proinflammatory and tumour proliferative properties of excess visceral adipose tissue. Cancer Lett. 312, 62-72.

Maity, P., Biswas, K., Chattopadhyay, I., Banerjee, R. K., and Bandyopadhyay, U. (2009). The use of neem for controlling gastric hyperacidity and ulcer. Phytother. Res. 23, 747-755.

Manikkam, M., Guerrero-Bosagna, C., Tracey, R., Haque, M. M., and Skinner, M. K. (2012). Transgenerational actions of environmental compounds on reproductive disease and identification of epigenetic biomarkers of ancestral exposures. PLoS ONE 7, e31901. doi:10.1371/journal.pone.0031901

Mantovani, A., Allavena, P., Sica, A., and Balkwill, F. (2008). Cancer-related inflammation. Nature 454, 436-444.

Medema, J. P., and Vermeulen, L. (2011). Microenvironmental regulation of stem cells in intestinal homeostasis and cancer. Nature 474, 318-326.

Meeker, J. D., and Ferguson, K. K. (2011). Relationship between urinary phthalate and bisphenol A concentrations and serum thyroid measures in U.S. adults and adolescents from the National Health and Nutrition Examination Survey (NHANES) 2007-2008. Environ. Health Perspect. 119, 1396-1402.

Meeran, S. M., Patel, S. N., Chan, T. H., and Tollefsbol, T. O. (2011). A novel prodrug of epigallocatechin3-gallate: differential epigenetic hTERT repression in human breast cancer cells. Cancer Prev. Res. (Phila.) 4, 1243-1254.

Mitchell, A. E., Hong, Y. J., Koh, E., Barrett, D. M., Bryant, D. E., Denison, R. F., and Kaffka, S. (2007). Tenyear comparison of the influence of organic and conventional crop management practices on the content of flavonoids in tomatoes. J. Agric. Food Chem. 55, 6154-6159.

Mizushina, Y., Saito, A., Horikawa, K. Nakajima, N., Tanaka, A., Yoshida, H., and Matsubara, K. (2011). Acylated catechin derivatives: inhibitors of DNA polymerase and angiogenesis. Front. Biosci. (Elite Ed.) 3 1337-1348.

Mizushina, Y., Saito, A., Tanaka, A., Nakajima, N., Kuriyama, I., Takemura, M., Takeuchi, T., Sugawara, F., and Yoshida, H. (2005). Structural analysis of catechin derivatives as mammalian DNA polymerase inhibitors. Biochem. Biophys. Res. Commun. 333, 101-109.
Mondal, D., Lopez-Espinosa, M. J., Armstrong, B., Stein, C. R., and Fletcher, T. (2012). Relationships of perfluorooctanoate and perfluorooctane sulfonate serum concentrations between child-mother pairs in a population with perfluorooctanoate exposure from drinking water. Environ. Health Perspect. 120, 752-757.

Muehlberg, F. L., Song, Y. H., Krohn, A., Pinilla, S. P., Droll, L. H., Leng, X., Seidensticker, M., Ricke, J., Altman, A. M., Devarajan, E., Liu, W., Arlinghaus, R. B., and Alt, E. U. (2009). Tissue-resident stem cells promote breast cancer growth and metastasis. Carcinogenesis 30, 589-597.

Mukherjee, S., Garg, S., and Talwar, G. P. (1999). Early post implantation contraceptive effects of a purified fraction of neem (Azadirachta indica) seeds, given orally in rats: possible mechanisms involved. J. Ethnopharmacol. 67, 287-296.

Muqbil, I., Beck, F. W., Bao, B., Sarkar, F. H., Mohammad, R. M., Hadi, S. M., and Azmi, A. S. (2012). Old wine in a new bottle: the warburg effect and anticancer mechanisms of resveratrol. Curr. Pharm. Des. 18, 1645-1654.

Nakagawa, H., Hasumi, K., Takami, M., Aida-Hyugaji, S., Woo, J. T., Nagai, K., Ishikawa, T., and Wachi, M. (2007). Identification of two biologically crucial hydroxyl groups of (-)-epigallocatechin gallate in osteoclast culture. Biochem. Pharmacol. 73, 34-43.

National Cancer Institute. (2005). Health information tip sheet for writers: cancer health disparities. Available at: http://www.cancer gov/newscenter/entertainment/ tipsheet/cancer-health-disparities [accessed January 21, 2012].

National Cancer Institute: President's Cancer Panel. (2009). Reducing Environmental Cancer Risk: What We Can Do Now. Available at: http://deainfo.nci.nih.gov/ advisory/pcp/annual

Reports/pcp0809rpt/PCP_Report_08-09_508.pdf [accessed January 7, 2012].

Oishi, K., Sato, T., Yokoi, W., Yoshida, Y., Ito, M., and Sawada, H. (2008) Effect of probiotics, Bifidobacterium breve and Lactobacillus casei, on bisphenol A exposure in rats. Biosci. Biotechnol. Biochem. 72, 1409-1415.

Olshansky, S. J., Passaro, D. J., Hershow, R. C., Layden, J., Carnes, B. A., Brody, J., Hayflick, L., Butler, R. N., Allison, D. B., and Ludwig, D. S. (2005). A potential decline in life 
expectancy in the United States in the 21 st century. N. Engl. J. Med.352, 1138-1145.

Panaro, M. A., Carofiglio, V., Acquafredda, A., Cavallo, P., and Cianciulli, A. (2012). Anti-inflammatory effects of resveratrol occur via inhibition of lipopolysaccharide-induced NF-карраB activation in Caco-2 and SW480 human colon cancer cells. Br. J. Nutr. 1-10. [Epub ahead of print].

Park, H. J., Yang, J. Y., Ambati, S., Della-Fera, M. A., Hausman, D. B., Rayalam, S., and Baile, C. A. (2008). Combined effects of genistein, quercetin, and resveratrol in human and 3T3-L1 adipocytes. J. Med. Food 11, 773-783.

Park, H. J., Yoon, S. H., Han, L. S., Zheng, L. T., Jung, K. H., Uhm, Y. K., Lee, J. H., Jeong, J. S., Joo, W. S., Yim, S. V., Chung, J. H., and Hong, S. P. (2005). Amygdalin inhibits genes related to cell cycle in SNU-C4 human colon cancer cells. World J. Gastroenterol. 11, 5156-5161.

Park, L. K., Friso, S., and Choi, S. W. (2012). Nutritional influences on epigenetics and age-related disease. Proc. Nutr. Soc. 71, 75-83.

Park, S. Y., Lee, Y. H., Choi, K. C., Seong, A. R., Choi, H. K., Lee, O. H., Hwang, H. J., and Yoon, H. G. (2011). Grape seed extract regulates androgen receptor-mediated transcription in prostate cancer cells through potent anti-histone acetyltransferase activity. J. Med. Food 14, 9-16.

Patra, S. K., Rizzi, F., Silva, A., Rugina, D. O., and Bettuzzi, S. (2008). Molecular targets of (-)epigallocatechin-3-gallate (EGCG): specificity and interaction with membrane lipid rafts. J. Physiol. Pharmacol. 59(Suppl. 9), 217-235.

Payne, C. M., Crowley-Skillicorn, C., Bernstein, C., Holubec, H., and Bernstein, H. (2011). Molecular and cellular pathways associated with chromosome 1p deletions during colon carcinogenesis. Clin. Exp. Gastroenterol. 4, 75-119.

Peng, G., Dixon, D. A., Muga, S. J., Smith, T. J., and Wargovich, M. J. (2006a). Green tea polyphenol (-)epigallocatechin-3-gallate inhibits cyclooxygenase- 2 expression in colon carcinogenesis. Mol. Carcinog. 45, 309-319.

Peng, G., Wargovich, M. J., and Dixon, D. A. (2006b). Anti-proliferative effects of green tea polyphenol EGCG on Ha-Ras-induced transformation of intestinal epithelial cells. Cancer Lett. 238, 260-270.
Piek, E., Sleumer, L. S., van Someren, E. P., Heuver, L., de Haan, J. R., de Grijs, I., Gilissen, C., Hendriks, J. M., van Ravestein-van Os, R. I., Bauerschmidt, S., Dechering, K. J., van Zoelen, E. J. (2010). Osteotranscriptomics of human mesenchymal stem cells: accelerated gene expression and osteoblast differentiation induced by vitamin D reveals c-MYC as an enhancer of BMP2-induced osteogenesis. Bone 46, 613-627.

Radhakrishnan, S., Reddivari, L., Sclafani, R., Das, U. N., and Vanamala, J. (2011). Resveratrol potentiates grape seed extract induced human colon cancer cell apoptosis. Front. Biosci. (Elite Ed.) 3, 1509-1523.

Rapp, U. R., Ceteci, F., and Schreck, R. (2008). Oncogene-induced plasticity and cancer stem cells. Cell Cycle $7,45-51$.

Resendis-Antonio, O., Checa, A., and Encarnacion, S. (2010). Modeling core metabolism in cancer cells: surveying the topology underlying the Warburg effect. PLoS ONE 5, e12383. doi:10.1371/journal.pone. 0012383

Risio, M. (2011). The grand challenges in GI tract cancers. Front. Oncol. 1:46. doi:10.3389/fonc.2011.00046

Rofstad, E. K., Mathiesen, B., Kindem, K., and Galappathi, K. (2006). Acidic extracellular $\mathrm{pH}$ promotes experimental metastasis of human melanoma cells in athymic nude mice. Cancer Res. 66, 6699-6707.

Rossi, F., Godani, F., Bertuzzi, T., Trevisan, M., Ferrari, F., and Gatti, S. (2008). Health-promoting substances and heavy metal content in tomatoes grown with different farming techniques. Eur. J. Nutr. 47, 266-272.

Ruzickova, K., Cobbing, M., Rossi, M., and Belazzi, T. (2004). Health Care Without Harm's Preventing Harm from Phthalates, Avoiding PVC in Hospitals. Available at: http://www.pehsu.org/research/ hsostenible/dehp/detailsdehp.pdf [accessed on January 15, 2012].

Sakamoto, H., Yokota, H., Kibe, R., Sayama, Y., and Yuasa, A. (2002). Excretion of bisphenol Aglucuronide into the small intestine and deconjugation in the cecum of the rat. Biochim. Biophys. Acta 1573, 171-176.

Salian, S., Doshi, T., and Vanage, G. (2009a). Perinatal exposure of rats to bisphenol A affects the fertility of male offspring. Life Sci. 85, 742-752.

Salian, S., Doshi, T., and Vanage, G. (2009b). Neonatal exposure of male rats to bisphenol A impairs fertility and expression of sertoli cell junctional proteins in the testis. Toxicology 265, 56-67.

Schleipen, B., Hertrampf, T., Fritzemeier, K. H., Kluxen, F. M., Lorenz, A., Molzberger, A., Velders, M., and Diel, P. (2011). ERbeta-specific agonists and genistein inhibit proliferation and induce apoptosis in the large and small intestine. Carcinogenesis 32, 1675-1683.

Shanle, E. K., and Xu, W. (2011). Endocrine disrupting chemicals targeting estrogen receptor signaling: identification and mechanisms of action. Chem. Res. Toxicol. 24, 6-19.

Shimizu, M., Fukutomi, Y., Ninomiya, M., Nagura, K., Kato, T., Araki, H., Suganuma, M., Fujiki, H., and Moriwaki, H. (2008). Green tea extracts for the prevention of metachronous colorectal adenomas: a pilot study. Cancer Epidemiol. Biomarkers Prev. 17, 3020-3025.

Shin, S. C., and Choi, J. S. (2009). Effects of epigallocatechin gallate on the oral bioavailability and pharmacokinetics of tamoxifen and its main metabolite, 4-hydroxytamoxifen, in rats. Anticancer Drugs 20, 584-588.

Silviera, M. L., Smith, B. P., Powell, J. and Sapienza, C. (2012). Epigenetic differences in normal colon mucosa of cancer patients suggest altered dietary metabolic pathways. Cancer Prev. Res. (Phila.) 5, 374-384.

Simopoulos, A. P. (2002). The importance of the ratio of omega6/omega-3 essential fatty acids. Biomed. Pharmacother. 56, 365-379.

Simopoulos, A. P. (2008). The omega6/omega-3 fatty acid ratio, genetic variation, and cardiovascular disease. Asia Pac. J. Clin. Nutr. 17(Suppl. 1), 131-134.

Sipos, F., Valcz, G., and Molnar, B. (2012). Physiological and pathological role of local and immigrating colonic stem cells. World J. Gastroenterol. 18, 295-301.

Strick, R., Strissel, P. L., Borgers, S., Smith, S. L., and Rowley, J. D. (2000). Dietary bioflavonoids induce cleavage in the MLL gene and may contribute to infant leukemia. Proc. Natl. Acad. Sci. U.S.A. 97, 4790-4795.

Subapriya, R., Velmurugan, B., and Nagini, S. (2005). Modulation of xenobiotic-metabolizing enzymes by ethanolic neem leaf extract during hamster buccal pouch carcinogenesis. J. Exp. Clin. Cancer Res. 24, 223-230.

Sultan, C., Balaguer, P., Terouanne, B., Georget, V., Paris, F., Jeandel, C., Lumbroso, S., and Nicolas, J.
(2001). Environmental xenoestrogens, antiandrogens and disorders of male sexual differentiation. Mol. Cell. Endocrinol. 178, 99-105.

Sundelacruz, S., Levin, M., and Kaplan, D. L. (2009). Role of membrane potential in the regulation of cell proliferation and differentiation. Stem Cell. Rev. 5, 231-246.

Swan, S. H., Liu, F., Hines, M., Kruse, R. L., Wang, C., Redmon, J. B., Sparks, A., and Weiss, B. (2010). Prenatal phthalate exposure and reduced masculine play in boys. Int. J. Androl. 33, 259-269.

Szkudelski, T., Nogowski, L., Pruszynska-Oszmalek, E., Kaczmarek, P., and Szkudelska, K. (2005). Genistein restricts leptin secretion from rat adipocytes. J. Steroid Biochem. Mol. Biol. 96, 301-307.

Tachibana, H., Koga, K., Fujimura, Y., and Yamada, K. (2004). A receptor for green tea polyphenol EGCG. Nat. Struct. Mol. Biol. 11, 380-381.

Takeshita, A., Inagaki, K., IgarashiMigitaka, J., Ozawa, Y., and Koibuchi, N. (2006). The endocrine disrupting chemical, diethylhexyl phthalate, activates MDR1 gene expression in human colon cancer LS174T cells. J. Endocrinol. 190, 897-902.

Tan, N. H., and Zhou, J. (2006). Plant cyclopeptides. Chem. Rev. 106, 840-895.

Tanabe, N., Yoshino, H., Kimoto, T., Hojo, Y., Ogiue-Ikeda, M., Shimohigashi, Y., and Kawato, S. (2012). Nanomolar dose of bisphenol A rapidly modulates spinogenesis in adult hippocampal neurons. Mol. Cell. Endocrinol. 351, 317-325.

Thomas, F., Holly, J. M., Persad, R., Bahl, A., and Perks, C. M. (2011). Green tea extract (epigallocatechin3-gallate) reduces efficacy of radiotherapy on prostate cancer cells. Urology 78, 475.e15-475.e21.

Tian, M., Peng, S., Martin, F. L., Zhang, J., Liu, L., Wang, Z., Dong, S., and Shen, H. (2012). Perfluorooctanoic acid induces gene promoter hypermethylation of glutathioneS-transferase $\mathrm{Pi}$ in human liver L02 cells. Toxicology 296, 48-55.

Tiwari, D., Kamble, J., Chilgunde, S., Patil, P., Maru, G., Kawle, D., Bhartiya, U., Joseph, L., and Vanage, G. (2012). Clastogenic and mutagenic effects of bisphenol A: an endocrine disruptor. Mutat. Res. 743, 83-90.

Tran, P. L., Kim, S. A., Choi, H. S., Yoon, J. H., and Ahn, S. G. (2010). Epigallocatechin-3-gallate suppresses the expression of HSP70 and HSP90 and exhibits anti-tumor activity in vitro and 
in vivo. BMC Cancer 10, 276. doi:10.1186/1471-2407-10-276

Tyagi, A., Agarwal, R., and Agarwal, C. (2003). Grape seed extract inhibits EGF-induced and constitutively active mitogenic signaling but activates JNK in human prostate carcinoma DU145 cells: possible role in antiproliferation and apoptosis. Oncogene 22, 1302-1316.

Umar, A., and Greenwald, P. (2009). Alarming colorectal cancer incidence trends: a case for early detection and prevention. Cancer Epidemiol. Biomarkers Prev. 18, 1672-1673.

Upham, B. L., Park, J. S., Babica, P., Sovadinova, I., Rummel, A. M., Trosko, J. E., Hirose, A., Hasegawa, R., Kanno, J., and Sai, K. (2009). Structure-activity-dependent regulation of cell communication by perfluorinated fatty acids using in vivo and in vitro model systems. Environ. Health Perspect. 117, 545-551.

Velmurugan, B., Singh, R. P., Agarwal, R., and Agarwal, C. (2010a). Dietary-feeding of grape seed extract prevents azoxymethaneinduced colonic aberrant crypt foci formation in fischer 344 rats. Mol. Carcinog. 49, 641-652.

Velmurugan, B., Singh, R. P., Kaul, N., Agarwal, R., and Agarwal, C. (2010b). Dietary feeding of grape seed extract prevents intestinal tumorigenesis in APCmin/+ mice. Neoplasia 12, 95-102.

Viberg, H., Fredriksson, A., Buratovic, S., and Eriksson, P. (2011). Dose-dependent behavioral disturbances after a single neonatal bisphenol A dose. Toxicology 290, 187-194.

Vom Saal, F. S., Nagel, S. C., Coe, B. L., Angle, B. M., and Taylor, J. A. (2012). The estrogenic endocrine disrupting chemical bisphenol A (BPA) and obesity. Mol. Cell. Endocrinol. 354, 74-84.
Wan, Y. J., Li, Y. Y., Xia, W., Chen, J., Lv, Z. Q., Zeng, H. C., Zhang, L., Yang, W. J., Chen, T., Lin, Y., Wei, J., and $\mathrm{Xu}, \mathrm{S}$. Q. (2010). Alterations in tumor biomarker GSTP gene methylation patterns induced by prenatal exposure to PFOS. Toxicology 274, 57-64.

Wang, L., Hao, J., Hu, J., Pu, J., Lu, Z., Zhao, L., Wang, Q., Yu, Q., Wang, Y., and Li, G. (2012a). Protective effects of ginsenosides against bisphenol Ainduced cytotoxicity in 15P-1 sertoli cells via extracellular signalregulated kinase $1 / 2$ signalling and antioxidant mechanisms. Basic Clin. Pharmacol. Toxicol. [Epub ahead of print].

Wang, P., Heber, D., and Henning, S. M. (2012b). Quercetin increased bioavailability and decreased methylation of green tea polyphenols in vitro and in vivo. Food Funct. [Epub ahead of print].

Wang, P., Aronson, W. J., Huang, M., Zhang, Y., Lee, R. P., Heber, D., and Henning, S. M. (2010). Green tea polyphenols and metabolites in prostatectomy tissue: implications for cancer prevention. Cancer Prev. Res. (Phila.) 3, 985-993.

Wang, Z., and Chen, H. (2010). Genistein increases gene expression by demethylation of WNT5a promoter in colon cancer cell line SW1116. Anticancer Res. 30, 4537-4545.

Weng, Y. I., Hsu, P. Y., Liyanarachchi, S., Liu, J., Deatherage, D. E., Huang, Y. W., Zuo, T., Rodriguez, B., Lin, C. H., Cheng, A. L., and Huang, T. H. (2010). Epigenetic influences of lowdose bisphenol A in primary human breast epithelial cells. Toxicol. Appl. Pharmacol. 248, 111-121.

Wishart, D. S., Knox, C., Guo, A. C., Eisner, R., Young, N., Gautam, B., Hau, D. D., Psychogios, N., Dong, E., Bouatra, S., Mandal, R., Sinelnikov, I., Xia, J., Jia, L., Cruz, J. A., Lim, E., Sobsey, C. A., Shrivastava, S., Huang, P., Liu, P., Fang, L., Peng,
J., Fradette, R., Cheng, D., Tzur, D., Clements, M., Lewis, A., De Souza, A., Zuniga, A., Dawe, M., Xiong, Y., Clive, D., Greiner, R., Nazyrova, A., Shaykhutdinov, R., Li, L., Vogel, H. J., and Forsythe, I.(2009). HMDB: a knowledgebase for the human metabolome. Nucleic Acids Res. 37, D603-D610.

Wolstenholme, J. T., Taylor, J. A., Shetty, S. R., Edwards, M., Connelly, J. J., and Rissman, E. F. (2011). Gestational exposure to low dose bisphenol A alters social behavior in juvenile mice. PLoS ONE 6, e25448. doi:10.1371/journal.pone.0025448

Xia, D., Wang, D., Kim, S. H., Katoh, H., and Dubois, R. N. (2012). Prostaglandin E(2) promotes intestinal tumor growth via DNA methylation. Nat. Med. 18, 224-226.

Yasui, K., Tanabe, H., Miyoshi, N., Suzuki, T., Goto, S., Taguchi, K., Ishigami, Y., Paeng, N., Fukutomi, R., Imai, S., and Isemura, M. (2011). Effects of (-)-epigallocatechin3-O-gallate on expression of gluconeogenesis-related genes in the mouse duodenum. Biomed. Res. 32, 313-320.

Yurino, H., Ishikawa, S., Sato, T., Akadegawa, K., Ito, T., Ueha, S., Inadera, H., and Matsushima, K. (2004). Endocrine disruptors (environmental estrogens) enhance autoantibody production by B1 cells. Toxicol. Sci. 81, 139-147.

Zhang, G., Wang, Y., Zhang, Y., Wan, X., Li, J., Liu, K., Wang, F., Liu, K., Liu, Q., Yang, C., Yu, P., Huang, Y., Wang, S., Jiang, P., Qu, Z., Luan, J., Duan, H., Zhang, L., Hou, A., Jin, S., Hsieh, T. C., and Wu, E. (2012a). Anti-cancer activities of tea epigallocatechin-3-gallate in breast cancer patients under radiotherapy. Curr. Mol. Med. 12, 163-176.

Zhang, L., Hou, D., Chen, X., Li, D. Zhu, L., Zhang, Y., Li, J., Bian, Z. Liang, X., Cai, X., Yin, Y., Wang,
C., Zhang, T., Zhu, D., Zhang, D., Xu, J., Chen, Q., Ba, Y., Liu, J., Wang, Q., Chen, J., Wang, J., Wang, M., Zhang, Q., Zhang, J., Zen, K., and Zhang, C. Y. (2012b). Exogenous plant MIR168a specifically targets mammalian LDLRAP1: evidence of cross-kingdom regulation by microRNA. Cell Res. 22, 107-126.

Zheng, T., Holford, T. R., Chen, Y., Ward, B., Liu, W., Flannery, J., and Boyle, P. (1997). Are cancers of the salivary gland increasing? Experience from Connecticut, USA. Int. J. Epidemiol. 26, 264-271.

Zink, A., Rohrbach, H., Szeimies, U., Hagedorn, H. G., Haas, C. J., Weyss, C., Bachmeier, B., and Nerlich, A. G. (1999). Malignant tumors in an ancient Egyptian population. Anticancer Res. 19, 4273-4277.

Conflict of Interest Statement: The authors declare that the research was conducted in the absence of any commercial or financial relationships that could be construed as a potential conflict of interest.

Received: 14 February 2012; accepted: 14 May 2012; published online: 01 June 2012.

Citation: Sokolosky ML and Wargovich MJ (2012) Homeostatic imbalance and colon cancer: the dynamic epigenetic interplay of inflammation, environmental toxins, and chemopreventive plant compounds. Front. Oncol. 2:57. doi: 10.3389/fonc.2012.00057

This article was submitted to Frontiers in Gastrointestinal Cancers, a specialty of Frontiers in Oncology.

Copyright (c) 2012 Sokolosky and Wargovich. This is an open-access article distributed under the terms of the Creative Commons Attribution Non Commercial License, which permits noncommercial use, distribution, and reproduction in other forums, provided the original authors and source are credited. 